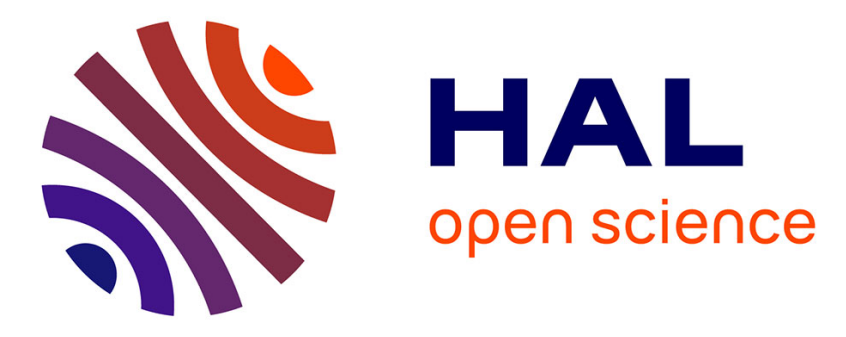

\title{
Wind profiler analysis of the African Easterly Jet in relation with the boundary layer and the Saharan heat-low
}

\author{
M. C. R. Kalapureddy, Marie Lothon, Bernard Campistron, Fabienne Lohou, \\ Frédérique Saïd
}

\section{To cite this version:}

M. C. R. Kalapureddy, Marie Lothon, Bernard Campistron, Fabienne Lohou, Frédérique Saïd. Wind profiler analysis of the African Easterly Jet in relation with the boundary layer and the Saharan heatlow. Quarterly Journal of the Royal Meteorological Society, 2010, 136 (S1), pp.77-91. 10.1002/qj.494 . hal-00993295

\section{HAL Id: hal-00993295 \\ https://hal.science/hal-00993295}

Submitted on 10 Sep 2021

HAL is a multi-disciplinary open access archive for the deposit and dissemination of scientific research documents, whether they are published or not. The documents may come from teaching and research institutions in France or abroad, or from public or private research centers.
L'archive ouverte pluridisciplinaire HAL, est destinée au dépôt et à la diffusion de documents scientifiques de niveau recherche, publiés ou non, émanant des établissements d'enseignement et de recherche français ou étrangers, des laboratoires publics ou privés. 


\title{
Wind profiler analysis of the African Easterly Jet in relation with the boundary layer and the Saharan heat-low
}

\author{
M. C. R. Kalapureddy, ${ }^{\mathrm{a}, \mathrm{b} *}$ M. Lothon, ${ }^{\mathrm{b}}$ B. Campistron, ${ }^{\mathrm{b}}$ F. Lohou ${ }^{\mathrm{b}}$ and F. Saïd ${ }^{\mathrm{c}}$ \\ ${ }^{a}$ Indian Institute of Tropical Meteorology, Ministry of Earth Sciences, Pune, India \\ ${ }^{\mathrm{b}}$ Centre de Recherches Atmospheriques, LA, CNRS, Campistrous, France \\ ${ }^{\mathrm{c}}$ Laboratoire d'Aérologie, Université de Toulouse, Toulouse, France
}

\begin{abstract}
Wind profiler measurements in Niger and Benin during the African Monsoon Multidisciplinary Analysis project are used to study the intraseasonal variability of the low and mid troposphere at several time-scales. We focus on the African Easterly Jet (AEJ) and its interaction with the Saharan Heat-Low (HL) and the planetary boundary layer (PBL).

We find a pronounced diurnal cycle of the AEJ, characterised by a decrease of wind speed during the afternoon, reaching a minimum at 1800 UTC of about $15-20 \%$ of the daily average during the pre-onset period. This decrease is out of phase with the HL intensity, but in phase with the daytime turbulent mixing associated with the PBL. The interaction between the PBL and mid-troposphere is likely responsible for this daily decrease of the AEJ.

During the transition periods (dry to wet or wet to dry), the HL seems to govern the AEJ; however, slightly before the monsoon onset, it has no direct influence on the jet. During that time, we find smaller AEJ wind speed for deeper PBL, as found at the diurnal time-scale. This is consistent with the still large surface heating at that time, which favours deep PBL growth, with a top inversion often higher than the shear layer between the monsoon and the easterlies. After the monsoon onset, deep convection, African Easterly Waves (AEWs) and dry intrusions make the synoptic environment complex and blur the interaction between AEJ and PBL. We still find weaker AEJ for deeper PBL, but likely without a direct connection between them.
\end{abstract}

KEY WORDS West African monsoon; AMMA; diurnal cycle; spectral analysis

\section{Introduction}

A complex dynamical structure governs the West African atmosphere during the boreal summer. The West African Monsoon (WAM) is a recurrent large-scale pattern arising from the thermal contrast existing between the warm African continent and the cooler southern Atlantic Ocean during the boreal summer. This meridional circulation results in the transport of moist air from the Atlantic and dry air from the Sahara. Thermal gradients, driven by the Heat-Low (HL) in both meridional and vertical planes, are responsible for the African Easterly Waves (AEWs) through barotropic instability (Burpee, 1972; Reed et al., 1977; Thorncroft, 1995) and the maintenance of the African Easterly Jet (AEJ) through baroclinic instability (Thorncroft and Blackburn, 1999). Therefore, the WAM circulation is typically characterized by the southwesterly monsoon flow at low levels, the existence of the AEJ in the middle troposphere and the Tropical Easterly Jet (TEJ) at upper levels. The TEJ is a thermal wind linked to the temperature difference between the Tibetan Plateau and the Indian Ocean. The evolution of

\footnotetext{
${ }^{*}$ Correspondence to: M. C. R. Kalapureddy, Indian Institute of Tropica Meteorology, Ministry of Earth Sciences, Dr Homi Bhabha Road, Pashan, Pune-411 008, India. E-mail: kalapureddy1@gmail.com
}

the monsoon and the distribution of monsoon precipitation are tied to the evolution of the AEJ and TEJ. In particular, the AEJ plays a dominant role in organizing rain-generating mesoscale convective systems associated with synoptic-scale AEWs (Diedhiou et al., 1999).

The AEJ forms at about $700 \mathrm{hPa}$ and around $15^{\circ} \mathrm{N}$. While it is known to be an approximate thermal wind resulting from the strong meridional gradient of temperature from the Gulf of Guinea to the Sahara (Burpee, 1972), the sources of its generation and maintenance, and the factors that govern its position and variability still raise a number of questions. Cook (1999) showed, with idealized Global Climate Model (GCM) experiments, that the temperature gradient alone cannot explain the AEJ; the gradient of soil moisture is crucial. Thorncroft and Blackburn (1999) expressed the question differently and showed that the equivalent potential temperature gradient at the origin of the jet is due to both dry convection occurring in the HL to the north and, to a lesser extent, deep convection in the Intertropical Convergence Zone (ITCZ) to the south.

Because of its close link with AEWs (Pytharoulis and Thorncroft, 1999; Hsieh and Cook, 2008) and mesoscale convective systems, the AEJ plays a crucial role in the WAM. Prior to the African Monsoon Multidisciplinary 
Analysis (AMMA: Redelsperger et al., 2006), most of the studies about AEJ and AEWs were based on climate models and reanalyses, most commonly at the seasonal time-scale. However, it is important to understand the WAM intraseasonal variability down to the diurnal timescale, which is closer to the scales of AEW activity. It is also important to document the interactions between the AEJ and the planetary boundary layer (PBL) below.

The AMMA observations allow for new and deeper insight into the intraseasonal scale down to the local time-scale, thanks to the emphasis placed on the Enhanced Observing Period (EOP) (2005-2007) and Special Observing Periods for the 2006 wet season. Couvreux et al. (2009) made the first intraseasonal study of water vapour content since Cadet and Nnoli (1987). Using European Centre for Medium-Range Weather Forecasts (ECMWF) analyses at an enhanced $0.25^{\circ}$ horizontal resolution and 6-hour time interval, as well as Global Positioning System (GPS), radiosoundings and profiler observations, they highlighted surges of the monsoon flow at a 3-5-day time-scale, which they linked with the variability of HL intensity. Lothon et al. (2008) confirmed and clarified the importance of the diurnal cycle in the low troposphere previously pointed out by Parker et al. (2005) in the context of HAPEX-Sahel (Goutorbe et al., 1997) and the JET 2000 project (Thorncroft et al., 2003).

Here we use the continuous measurements of Ultra High Frequency (UHF) and Very High Frequency (VHF) wind profilers deployed respectively at two sites, Niamey in Niger and Djougou in Benin, during AMMA, to study the intraseasonal variability of the low and mid troposphere and their interactions down to the diurnal time-scale. The experimental dataset is described in the next section. Section 3 shows the seasonal variability of dynamical structures of West Africa over 2006 and 2007 and section 4 gives preliminary insights into the interaction between the mid and low troposphere and the boundary layer processes.

\section{Experimental set-up and dataset}

The two five-beam wind profilers used are UHF (915 MHz) and VHF (45 MHz) Doppler radars designed to detect backscattered signals from turbulence-induced atmospheric refractive index irregularities at a scale of half the radar wavelength (Bragg scattering mechanism) transported by the flow (e.g. Balsley and Gage, 1982; Strauch et al., 1984). Observations of at least three different directions permit the extraction of the three components of the wind $(u, v$ and $w)$, under the assumption of local horizontal homogeneity of the wind field. The radar reflectivity related to the structure parameter of the turbulence refractive index fluctuations $C_{n}{ }^{2}$ (e.g. Gossard et al., 1982) is deduced from the zero-order moment of the radar velocity spectrum measured by each beam at different heights. $C_{n}{ }^{2}$ characterizes the intensity of the refractive index fluctuations in the inertial subrange. A sudden increase of $C_{n}{ }^{2}$ with height is usually associated with sharp changes in atmospheric temperature and humidity under turbulent mixing. This is notably seen at the top of the boundary layer, and hence $C_{n}{ }^{2}$ can be used to estimate the boundary layer depth $Z_{i}$ (Doviak and Zrnic, 1993; Angevine et al., 1994; Jacoby-Koaly et al., 2002; Kalapureddy et al., 2007). In clear-air conditions, the capability of UHF profilers to detect a signal depends on the turbulence intensity. The return signal decreases as a function of range due to the combined reduction of turbulence and water vapour concentration, which often limits the height coverage. The typical accuracy of wind measurements with a profiler is about $1.5 \mathrm{~m} \mathrm{~s}^{-1}$ (Strauch et al., 1987; May, 1993; Adachi et al., 2005). It should be noted that wind profilers can also work in precipitation conditions, but the scattering mechanism associated with precipitation echo is different from the clear-air echo. Usually these two types of echoes can be separated in the VHF band but not in the UHF band due the dominance of particle scattering over clear-air turbulent scattering (Sato et al., 1990; Rao et al., 2001). Therefore, UHF radars are more sensitive to the precipitation echo, which masks the clear-air echo.

The measurements of UHF and VHF wind profilers operated respectively at Niamey (Niger, $13.48^{\circ} \mathrm{N}, 2.17^{\circ} \mathrm{E}$, $205 \mathrm{~m}$ ) and Nangatchori (Benin, $9.65^{\circ} \mathrm{N}, 1.73^{\circ} \mathrm{E}, 432 \mathrm{~m}$ ) were used during the AMMA EOP. We hereafter refer to the Benin site as 'Djougou', which is a town near Nangatchori. The two areas differ significantly from one another, with an annual rainfall in Benin of $1200 \mathrm{~mm}$ versus $500 \mathrm{~mm}$ in Niger. Since the wet season lasts much longer in Benin, the surface is more densely covered with vegetation (agriculture) whereas the area in Niamey has a large proportion of bare soil and tiger bushes. The two profilers were operated in continuous mode during the EOP, on the basis of a repetitive sequence of about 5 and 20 minutes duration for the UHF and VHF profilers, respectively. The experimental specifications used for the two radars are presented in Table I. A detailed description of the data processing can be found in Jacoby-Koaly et al. (2002).

In Niamey, the UHF radar was operated by the Atmospheric Radiation Measurement (ARM) facilities from 4 April 2006 to 6 January 2007 with almost no intermission, except for an inactive period from 17 June to 2 July 2006 due to technical problems. The high mode observation for this profiler ranges from 0.33 to $6.42 \mathrm{~km}$ with a radial resolution of $210 \mathrm{~m}$ (Table I). In Djougou, the VHF profiler was operated by the National Centre for Meteorological Research (CNRM) of the French meteorological institute (Météo-France). It was in operation from 25 April 2006 to 10 November 2007, with a break from 7 December 2006 to 22 January 2007 due to a transmitter failure. This resulted in a different calibration constant before and after the intermission. The vertical resolution of the VHF profiler is $375 \mathrm{~m}$ and the first measurement level starts at $1.5 \mathrm{~km}$ above ground level (a.g.l.). The presence of the equatorial electrojet centred at about $100 \mathrm{~km}$ altitude above Djougou was the source of strong and continuous returns. A data collection mode was adapted to prevent multiple trip echoes from the electrojet, unfortunately at the expense 
Table I. Technical characteristics of the two wind profilers.

\begin{tabular}{lcc}
\hline Profiler type & VHF & UHF \\
\hline Location & Djougou & Niamey \\
& $9^{\circ} 4^{\prime} \mathrm{N}, 1^{\circ} 4^{\prime} \mathrm{E}$ & $13^{\circ} 3^{\prime} \mathrm{N}, 2^{\circ} 1^{\prime} \mathrm{E}$ \\
& $432 \mathrm{~m}$ asl & $205 \mathrm{~m}$ asl \\
Antenna $\left(\mathrm{m}^{2}\right)$ & 60 & 4 \\
Frequency $(\mathrm{MHz})$ & 45 & 915 \\
Wavelength $(\mathrm{m})$ & 6.6 & 0.33 \\
Peak power $(\mathrm{kW})$ & 12 & 0.5 \\
Beam width $(\mathrm{deg})$ & 5.5 & 6 \\
Oblique angle $(\mathrm{deg})$ & 15 & 23 \\
Number of beams & 5 & 5 \\
Incoherent & 2 & $51 / 50$ \\
integrations & & \\
Pulse repetition & 2136 & 20000 \\
frequency (Hz) & & \\
Pulse length (m) & 750 coded & 420 \\
Range resolution (m) & 375 & $210 / 60$ \\
Time resolution $(\mathrm{min})$ & 20 & 5 \\
Height coverage $(\mathrm{km})$ & $1.5-22$ & $0.33-6.42$ \\
\hline
\end{tabular}

of radar sensitivity, which was for the most part limited below $12 \mathrm{~km}$. This prevented the full observation of the Tropical Easterly Jet.

Taking into account the data coverage indicated above, the two profilers allowed us to make statistical and spectral analyses of the AEJ and boundary layer dynamics. To complement our analysis, we also used ECMWF analyses for a three-dimensional overview of the spatial and temporal variability at large scale.

\section{Seasonal variability of the African Easterly Jet}

As mentioned in the introduction, the AEJ is a mesoscale dynamical feature of the WAM, governed primarily by the thermal gradient with diurnal to seasonal variability. At the same time, due to its altitude and origin, we expect some interactions between the AEJ and the underlying monsoon flow, as well as some impact of the PBL at the diurnal time-scale. Before studying the relationship between AEJ, HL and PBL, the following spectral analysis provides insight into the energy associated with the induced variability of the AEJ.

\subsection{Spatial and temporal variability}

Bock et al. (2008) defined four seasons over West Africa for the year 2006, based on precipitation and integrated water vapour. This results in common seasons for all of West Africa, which is the usual approach of climate studies, often based on the ITCZ position and especially on its pronounced shift northward at the start of the most active monsoon phase (Sultan and Janicot, 2000). For an overall picture of the dynamics at the height of the AEJ in 2006 and 2007 and at two different sites, we first consider the same periods as Bock et al. (2008):
Pre-monsoon (Pr) in April-May-June, Monsoon (M) during July-August-September, Post-monsoon (Po) during October-November and Dry (D) from December to March. The only discrepancy is November, which we considered to be part of the Post-monsoon period due to some signs of monsoon retreat episodes in reflectivity and vertical wind velocity.

The AEJ is typically located between 700 and $600 \mathrm{hPa}$ (Burpee, 1972; Reed et al., 1977), and the $700 \mathrm{hPa}$ level has been widely used for AEJ analysis (Redelsperger et al., 2002; Pytharoulis and Thorncroft, 1999). Figure 1 shows the horizontal wind at $700 \mathrm{hPa}$ and temperature at $925 \mathrm{hPa}$ using ECMWF analyses, on average over each season for 2006. The Intertropical Discontinuity (ITD) averaged position deduced from the ECMWF $2 \mathrm{~m}$ dew-point temperature (Lothon et al., 2008) is also indicated. The maximum of the easterlies at $700 \mathrm{hPa}$ is always positioned 2 to 5 degrees south of the ITD, closely connected to the meridional gradients of temperature and moisture. Like the ITD, they move northward during the monsoon onset and southward during its retreat. During the monsoon season, the AEJ is centred around $15^{\circ} \mathrm{N}$, with wind speed around $10 \mathrm{~m} \mathrm{~s}^{-1}$ at $700 \mathrm{hPa}$ on average all over West Africa and larger on the western coasts. During the transition periods Pr and Po, the ITD crosses the latitudes of Niamey and Djougou successively and the easterlies are close to the Guinea coast. In the boreal winter, the ITD approaches the coast. In fact, easterlies form a jet of lesser meridional extent during the peak of the monsoon, when the equivalent potential temperature gradient is the largest. Figure 1 shows that a profiler located in Djougou sees maximum easterly winds at $700 \mathrm{hPa}$ during the $\mathrm{Pr}$ and Po periods, while a profiler in Niamey will see it mainly in the $\mathrm{M}$ season. The westerlies over North Africa are associated with the Subtropical Jet (STJ), the core of which is higher in altitude (around $200 \mathrm{hPa}$ ) but which covers a deep part (down to $3 \mathrm{~km}$ height) of the troposphere (Figure 3), even over Niamey. It can reach $13^{\circ} \mathrm{N}$ during the boreal winter, when it is in its southward migration.

Figures 2 and 3 show time-height cross-sections of the wind measured at Djougou and Niamey, respectively, by the VHF and UHF profilers throughout their total EOP operation. The data are smoothed with a 24-hour running mean in order to filter out the diurnal cycle. As noted from the ECMWF analyses, the AEJ is seen over Djougou during $\mathrm{Pr}$ and Po periods (Figure 2) and in the $\mathrm{M}$ period to a lesser extent. It is observed over Niamey during the wet season, from mid-May to mid-October (Figure 3); that is, over a duration that covers the entire $\mathrm{M}$ period and part of the Pr and Po periods. The point of view of a profiler is of course singular, but the use of two sites and complementary ECMWF analyses helps us to understand the vertical dynamical structure observed by each profiler.

As seen in Figure 2, easterlies occupy all of the mid and upper troposphere from $2 \mathrm{~km}$ up to more than $10 \mathrm{~km}$ during the whole year over Benin with maxima during the Pr and Po periods, when the AEJ is above Djougou. The 
(a)

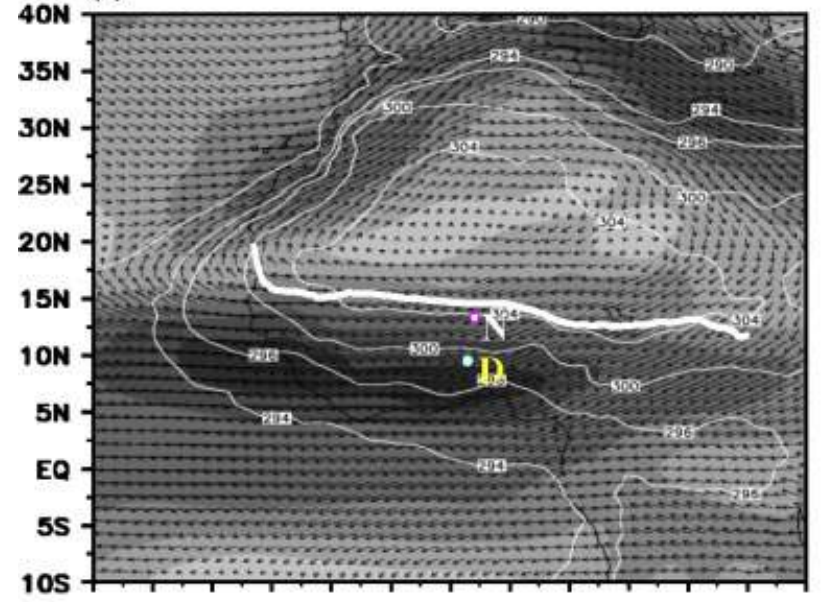

(c)

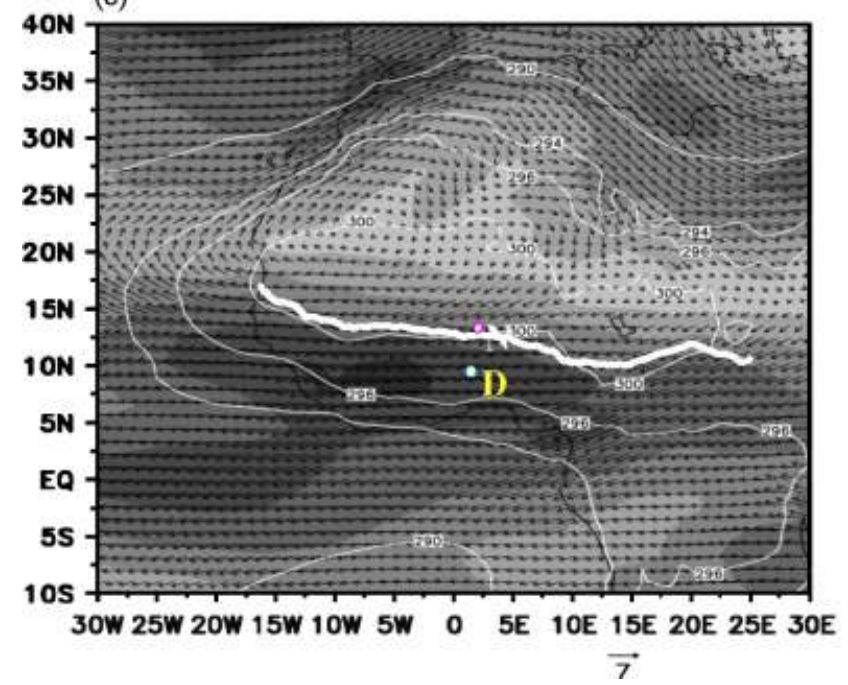

(b)

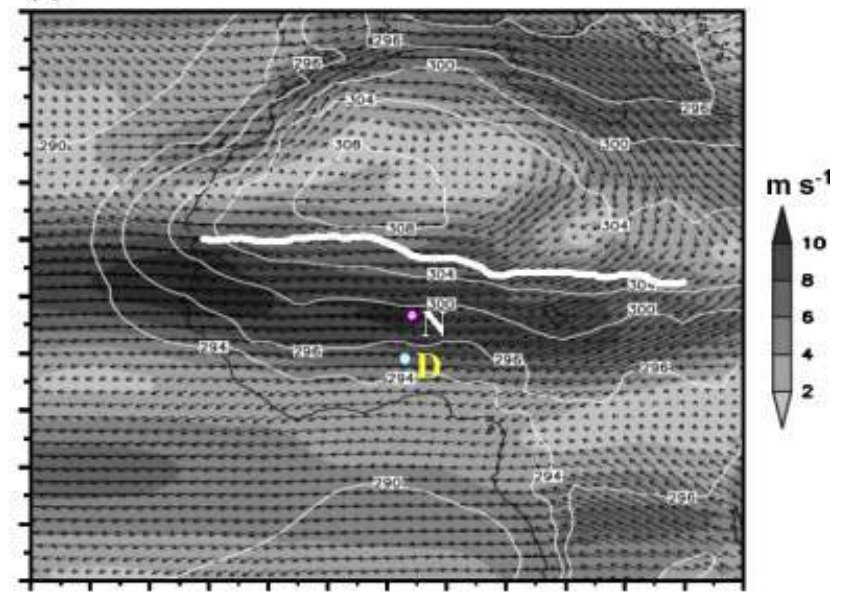

(d)

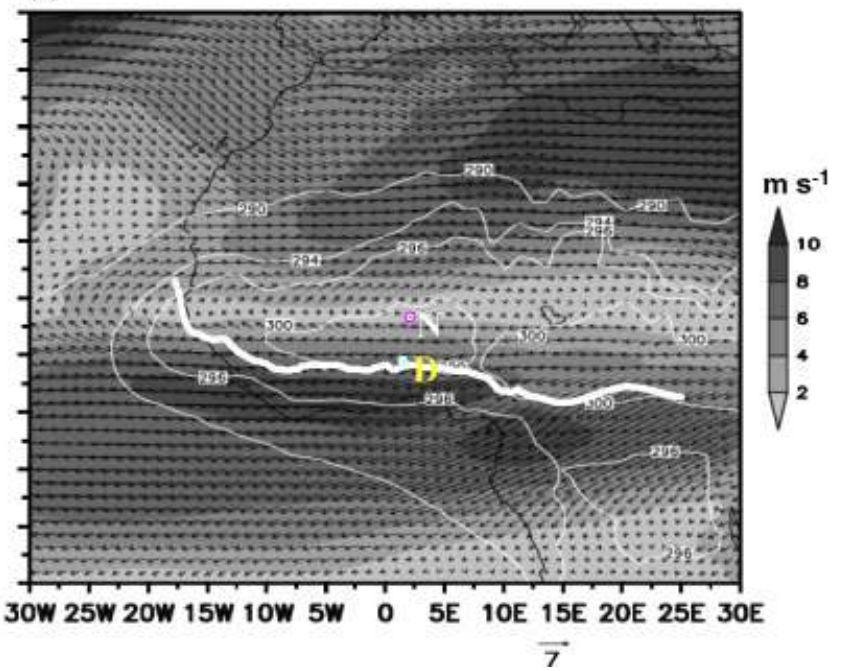

Figure 1. (grey scale and arrows) ECMWF horizontal wind at $700 \mathrm{hPa}$, (thin white lines) temperature at $925 \mathrm{hPa}$ and (thick white line) ITD position at surface averaged over the four seasons of 2006: (a) Pre-monsoon (AMJ) (b) Monsoon (JAS) (c) Post-monsoon (ON) (d) Dry season (DJFM). Profiler sites are indicated with circles (' $\mathrm{N}$ ' for Niamey and ' $\mathrm{D}$ ' for Djougou). This figure is available in colour online at www.interscience.wiley.com/journal/qj

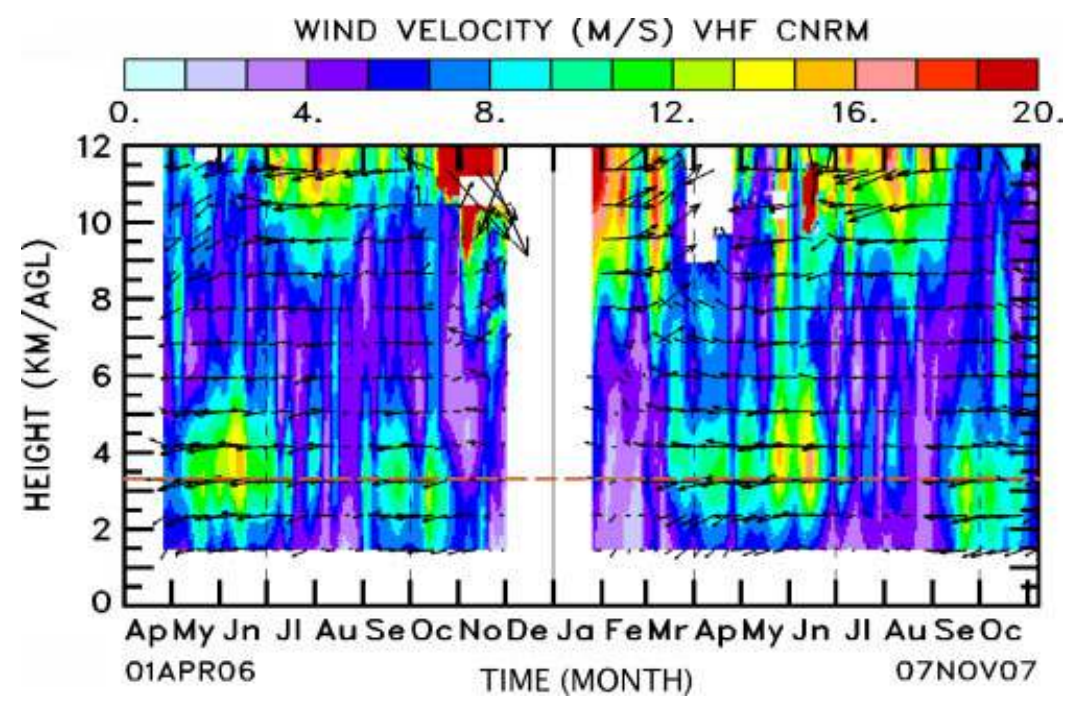

Figure 2. Time-height cross-section of the horizontal wind measured with the VHF wind profiler in Djougou from 25 April 2006 to 10 November 2007. A leftward arrow represents an easterly wind. The orange dashed line indicates the $3.3 \mathrm{~km}$ height at which time series are analysed later in the text (see Figure 4(c)-(d)). This figure is available in colour online at www.interscience.wiley.com/journal/qj 


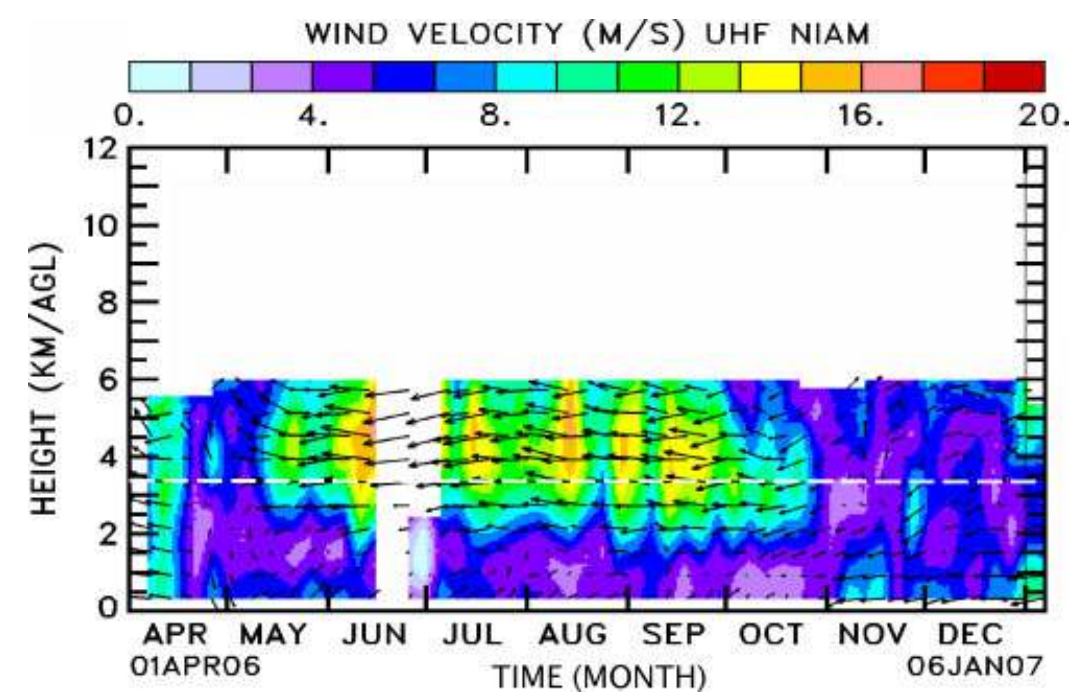

Figure 3. Same as Figure 2, but for Niamey UHF wind profiler from 4 April 2006 to 6 January 2007. The white dashed line indicates the 3.3 km height at which time series and spectra are analysed later in the text (see Figures 4(a)-(b), 6 and 7). This figure is available in colour online at www.interscience.wiley.com/journal/qj

low-level southerly monsoon flow, with a depth of about $1.5 \mathrm{~km}$, cannot be seen with the VHF profiler, which starts its observation at a height of $1.5 \mathrm{~km}$ a.g.l. In Niamey, the easterlies are also the prevailing wind in the midtroposphere (Figure 3), but southwesterly winds are often observed during the dry season, which can correspond to the lower flank of the STJ. Intrusions of the STJ over Benin, more to the south, are scarce. The TEJ is barely observed with the VHF (Figure 2), with speeds around $20 \mathrm{~m} \mathrm{~s}^{-1}$, and as explained in the previous section, it was neither possible to fully cover its extent nor to be confident in the measurements made in this high-level jet. Looking more carefully at Figures 2 and 3, one can see that the AEJ vertical structure changes during the course of the year, with higher core and deeper jet during the monsoon season (Figure 3) than during the $\mathrm{Pr}$ and $\mathrm{Po}$ monsoon seasons (Figure 2). Over Benin during the $\mathrm{Pr}$ period, the AEJ core height is located around $3.3 \mathrm{~km}$ a.g.l., increasing as the monsoon sets in, and decreases to $3 \mathrm{~km}$ during the Po period. The AEJ is about 2 to $3 \mathrm{~km}$ deep and always around $12 \mathrm{~m} \mathrm{~s}^{-1}$. In Niamey during the $\mathrm{M}$ period, it is around $4.5 \mathrm{~km}$ in height, with a depth of about 4 to $5 \mathrm{~km}$. This is due to the increase of surface heating gradient from $5 \mathrm{~K}$ in early May to $12 \mathrm{~K}$ in early July associated with an increase in the altitude at which the horizontal temperature gradient vanishes (corresponding to the maximum of the jet). While the core of the AEJ is sampled continuously by the UHF profiler (Figure 3), its full extent with maximum height above $6 \mathrm{~km}$ cannot be observed in all situations.

The dynamics of the lower layers are well described by the UHF profiler in Niamey over the entire year (Figure 3). Below $1.5 \mathrm{~km}$ in height, the change from the southwesterly monsoon flow in the wet season to the northeasterly harmattan in the dry season is visible. Harmattan is generally associated with larger wind speeds. The transition periods, $\operatorname{Pr}$ and $\mathrm{Po}$, are usually associated with alternation of both flows at several-day and diurnal periods (with monsoon during the night and early morning, and harmattan during the day), as mentioned by Lothon et al. (2008). Figure 3 shows that the monsoon flow is stronger and deeper in the $\mathrm{Pr}$ period than during the $\mathrm{M}$ phase.

Figure 4 focuses on the AEJ, with time series of daily mean wind speed and wind direction at $3.3 \mathrm{~km}$ a.g.l. above both sites, measured by the same two profilers as in Figures 2 and 3. The ECMWF analyses at $700 \mathrm{hPa}$ are superimposed with the same time resolution. Even if it is not our purpose here to validate the ECMWF analysis, we take advantage of Figure 4 to note a good agreement between the analyses and the profiler measurements (correlation coefficient of 0.9 and bias of $\left.1 \mathrm{~m} \mathrm{~s}^{-1}\right)$. The radiosoundings of Niamey and Parakou, $100 \mathrm{~km}$ from Djougou, are partly assimilated, which explains this close agreement to some extent. However, the impact of the assimilation changes over the course of the year as the sampling frequency varies, with higher frequency during the summer for both stations, and a generally denser sampling over Niamey. Insight into the significant variability of the AEJ at the different sites and at different scales revealed by this figure is provided in the following spectral analysis.

\subsection{Spectral analysis}

We now consider, for the remainder of the article, the observations made by the profiler in Niamey, due to the high data coverage that enables us to study the predominant periodicities and associated processes.

Figure 1 showed how, as 'seen' from a specific site, the season depends on the position of the ITD relative to the considered site. In the lower troposphere in particular, the ITD relative position determines whether the flow is the moist southwesterly monsoon or the dry northeasterly harmattan. In the rest of the article, as we analyse 

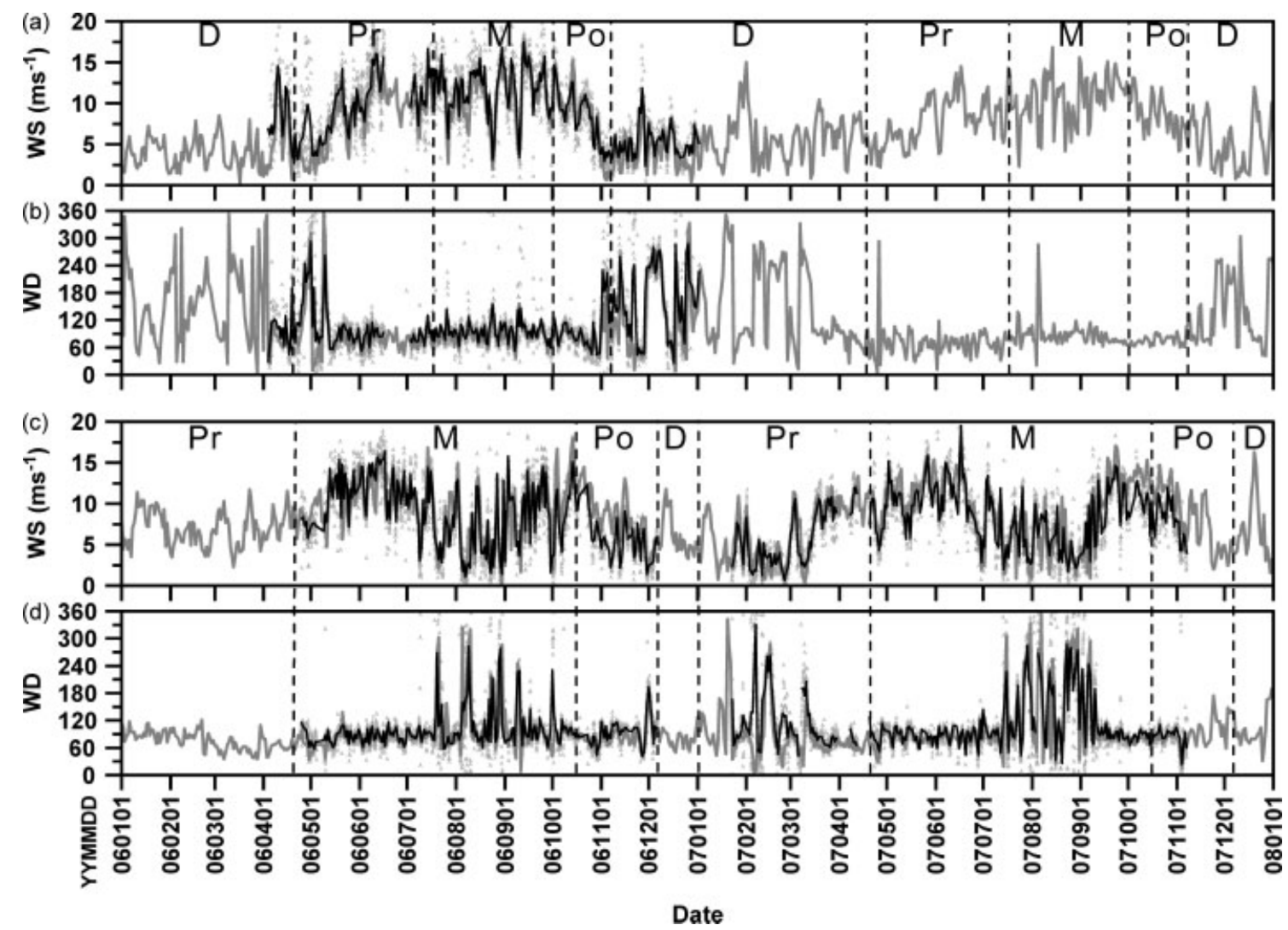

Figure 4. Horizontal (a)(c) wind speed and (b)(d) direction at $700 \mathrm{hPa}(3.3 \mathrm{~km})$ over (a)(b) Niamey and (c)(d) Djougou during the entire years 2006 and 2007, according to (thick grey line) ECMWF analyses and to (grey triangles) superimposed UHF/VHF observations at 15 min time intervals or (black thin solid line) averaged at 6-hour time intervals. Vertical dashed lines separate the four seasons.

the observations from the point of view of a profiler, including the low troposphere, we consider different dates for the sequencing of $\mathrm{Pr}, \mathrm{M}, \mathrm{Po}$ and D periods fully adapted to the Niamey site. For this, we use the same definition used by Lothon et al. (2008), based on the position of the ITD, the associated wind in the low troposphere, and humidity. For Niamey in 2006, this yields the following: Pr from 17 April to 15 July, M from 16 July to 1 October, Po from 2 October to 6 November and D from 7 November to the end of 6 January 2007 (end of dataset). Those periods are in fact relatively close to the general seasons given by Bock et al. (2008).

Spectra of both wind components $U$ and $V$ are displayed in Figures 5 and 6 respectively, made with the measurements of the Niamey profiler, for each of the four seasons defined just above and at two levels: one within the AEJ level $(3000 \mathrm{~m})$, and one in the lower troposphere $(500 \mathrm{~m})$, within the harmattan (during D period) or monsoon flows. We can split the time-scales into two interval bins: (1) periods $>1$ day and $<10$ days, and $(2) \leqslant 1$ day.

(1) Both wind components show some spectral peaks at the periods $>1$ and $<10$ days, at both levels. Several key processes of the WAM occur within this range. The welldocumented AEWs are one of them, with periodicities of 3-5 days (Burpee, 1972; Thorncroft and Hodges, 2001; Lavaysse et al., 2006). They are by definition associated with spatial and temporal variability of the AEJ, and expected to occur mainly during the $M$ period in the mid-troposphere. Thus the peaks of the mid-troposphere indicated in Figures 5(b) and 6(b) are likely associated with AEWs. It was also shown that AEWs can be observed down to the lower troposphere (Kiladis et al., 2006), which can explain the fact that peaks are observed at the same scales in the lower levels during the $\mathrm{M}$ season in Figures 5(b) and 6(b).

Another source of variability at this scale is due to the monsoon flow variability in the low troposphere: surges of the south-westerly monsoon flow were observed by Couvreux et al. (2009), who showed that the monsoon flow can penetrate further inland and over a deeper layer via surge tongues that result in bursts of water vapour over the Sahel region with variability at the time-scale of a few days, like the AEWs. These surges occur mainly during the Pr and Po transition periods and are linked to the HL variability. They can explain the oscillations peaks in Figure 5(a)-(c) and Figure 6(a)-(c). These peaks are also shown to be linked to the variability of the HL intensity, which pumps the monsoon flow as it deepens, with a negative feedback caused by the decrease of the temperature gradient made by the advection of cooler and moister air.

Although they have distinct preferential periods, the two processes, AEWs and monsoon surges (MS), can interact. According to Couvreux et al. (2009), some of the monsoon surges propagate westward with the AEWs, 
(a)

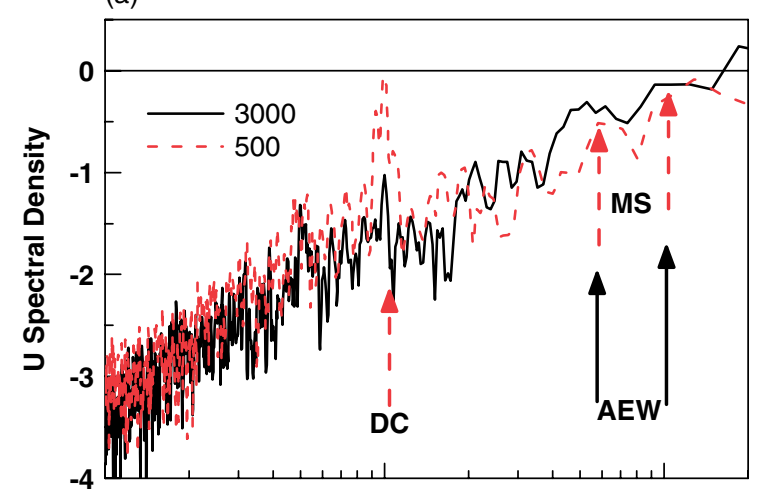

(c)

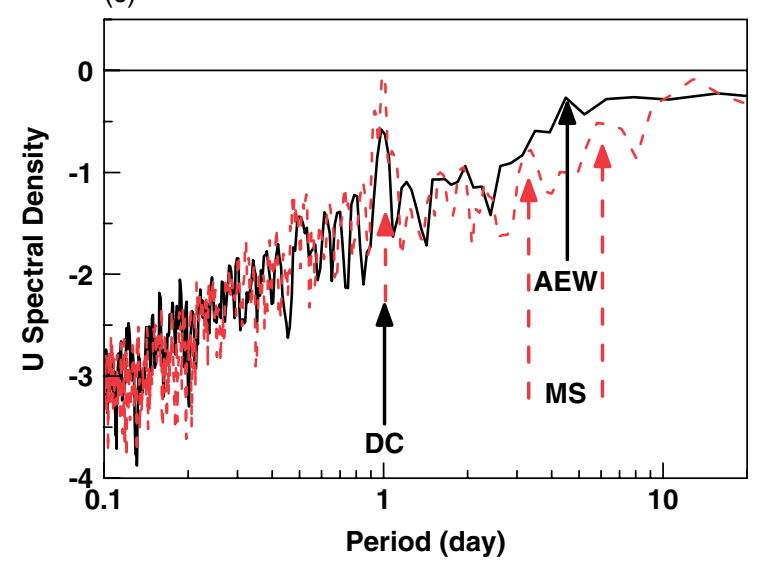

(b)

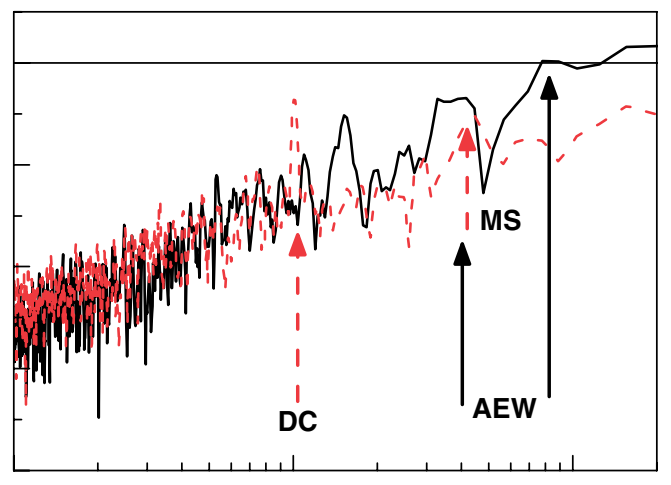

(d)

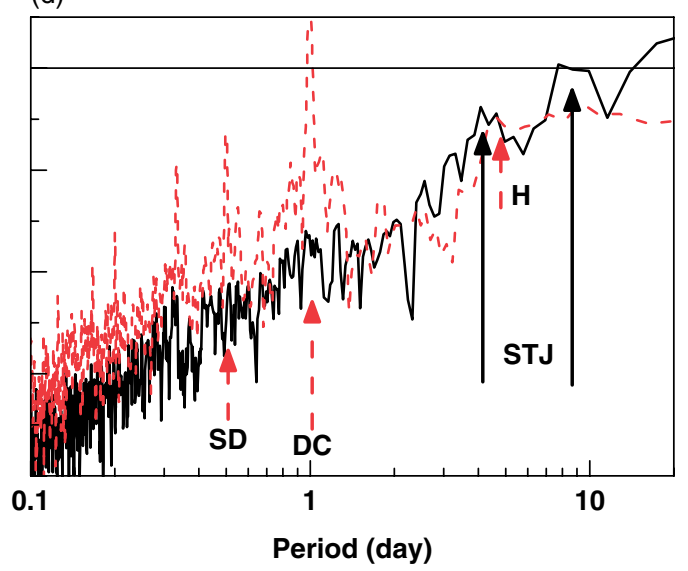

Figure 5. Spectra of the zonal wind component, $U$, at (red) $500 \mathrm{~m}$ and (black) $3000 \mathrm{~m}$ a.g.l. obtained during (a) Pr, (b) M, (c) Po, and (d) D. The arrows point out specific processes or WAM components (Monsoon Surges (MS), African Easterly Waves (AEW), Diurnal Cycle (DC),

Harmattan (H), and Subtropical Jet (STJ)). This figure is available in colour online at www.interscience.wiley.com/journal/qj

and some do not. That is, the pulsation of the monsoon, which results in local increase of southerly wind and water vapour, can move toward the west with time, or simply retreat to the south (local decrease in time). The authors demonstrated this phenomenon using Hovmüller diagrams of wind speed and precipitable water. They found that half of the surges are stationary whereas the other half propagate westwards.

Both the AEWs activity and the monsoon surges are consistent with an increase of energy in the wind components, with a larger contribution from the meridional component than from the zonal component. This may explain the generally larger quantity of energy found for the $V$ component at this time-scale in Figure 6 relative to Figure 5. According to Cook (1999), most of the ageostrophic wind in the AEJ is carried by the meridional component, whereas the zonal component creates most of the geostrophic wind. Pytharoulis and Thorncroft (1999) also found that low-level waves formed at the northern or southern flanks of the AEJ are responsible for larger variance of the meridional component.

Another process involved at these scales is deep convection, which modifies the horizontal wind through the vertical velocity energy increase. It is known that deep convection in the WAM often triggers in one flank or the other of the AEJ (south or north), in the tail of AEWs, and is fed by the humidity brought into the low troposphere by the monsoon flow (Fink and Reiner, 2003). This shows the extreme coupling of all the processes at this timescale: AEWs, monsoon flow, deep convection, HL and AEJ all reveal a predominant variability at the 3-5day scale. Several recent works published in the present issue confirm this (Couvreux et al., 2009; Lavaysse et al., 2009b).

In the $\mathrm{D}$ period, there is still some energy in both components and at both levels. We find in general more energy at low level than at $3 \mathrm{~km}$ height for this season, due to a general decrease of wind in the latter case (see Figure 7 later). The peaks at time-scales $>1$ day at $3 \mathrm{~km}$ are due to several intrusions of the upper-level STJ down to the mid-troposphere. These intrusions are depicted in Figure 4(b) by changes in wind direction from northeasterlies (harmattan) to southwesterlies (STJ). At $500 \mathrm{~m}$, the energy is associated with the intraseasonal variability of the harmattan $(\mathrm{H})$.

(2) At smaller scales, the diurnal cycle (DC) stands out very clearly during almost every season and for both wind components at low levels (see Figures 5 and 6). This is due to the existence of a nocturnal jet forming overnight and until the morning (with a maximum in the early morning, as shown by Lothon et al. (2008)), and the supplemental effect of the daytime dry convection in the mixed layer that weakens the mean wind in the lower troposphere. The peak is significantly higher 
(a)

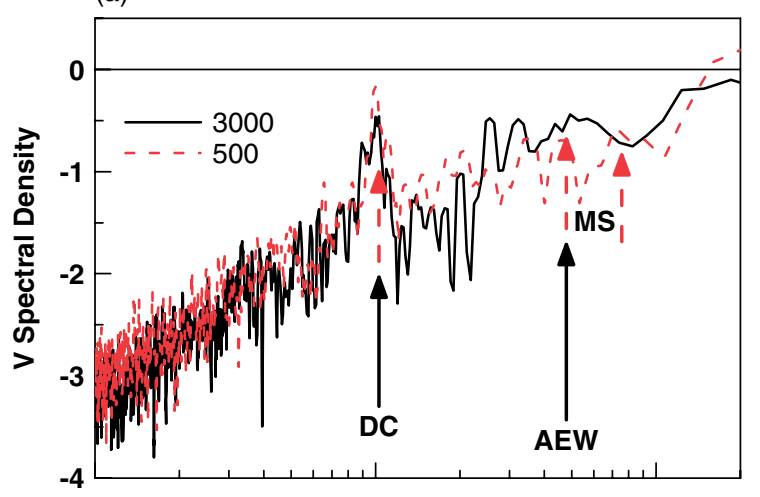

(c)

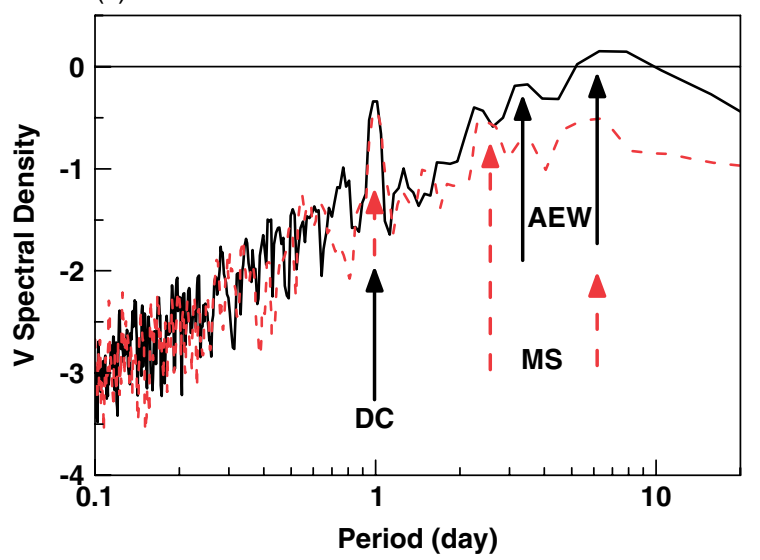

(b)

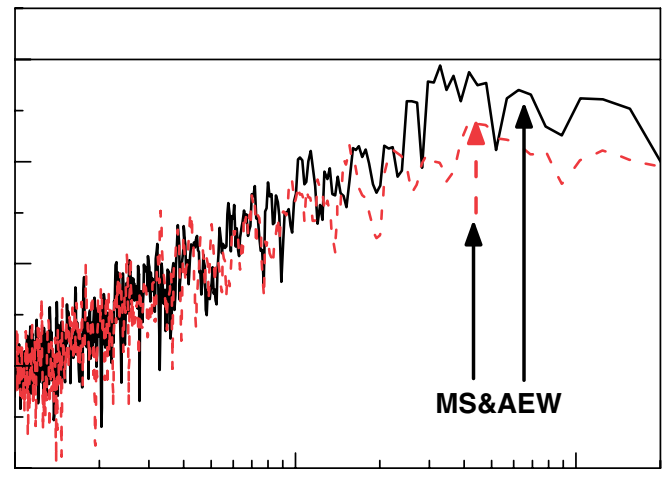

(d)

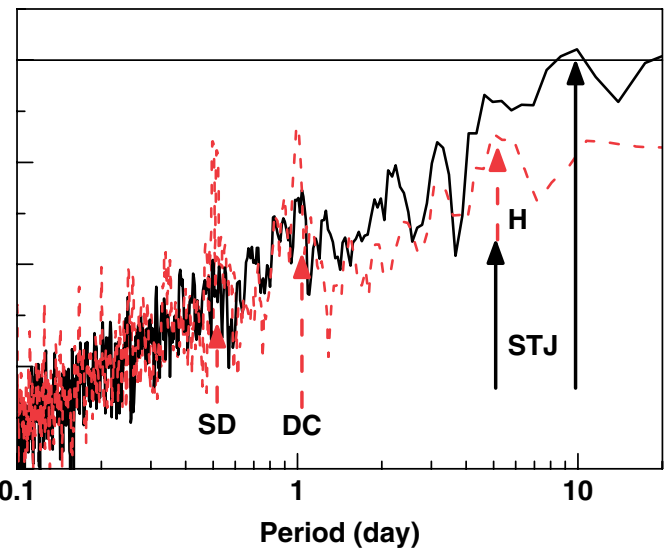

Figure 6. Same as Figure 5, but for the meridional wind component, $V$. This figure is available in colour online at www.interscience.wiley.com/journal/qj

(a) WIND VELOCITY (M/S) UHF NIAM

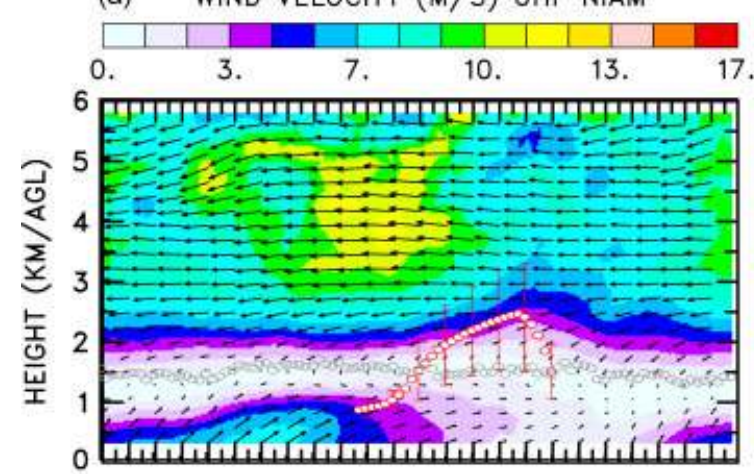

(c)

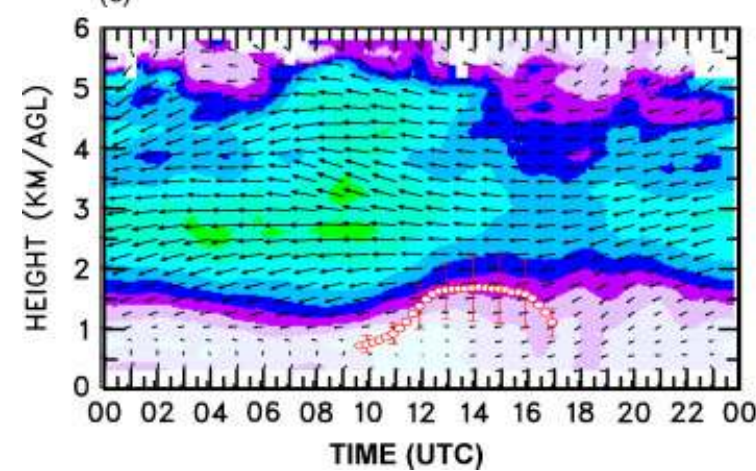

(b) WIND VELOCITY (M/S) UHF NIAM
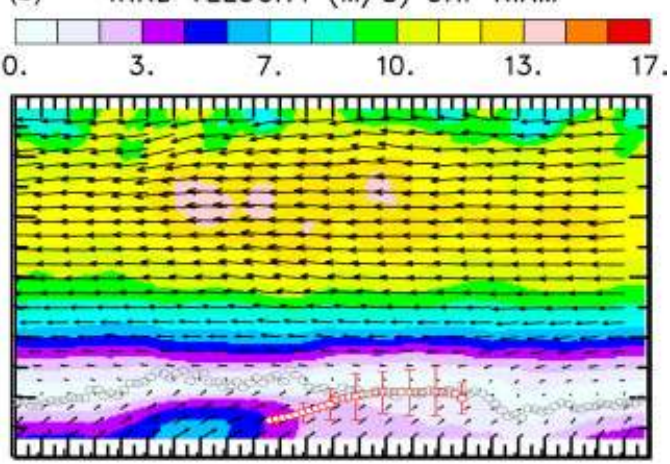

(d)

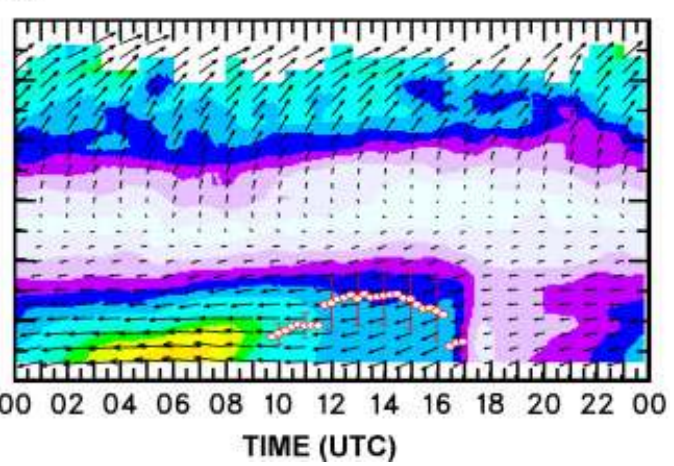

Figure 7. Composite day of (colour scale and arrows) the horizontal wind, (red dots) PBL height and (grey circles) height of the minimum wind speed obtained during (a) Pr, (b) M, (c) Po, and (d) D periods over Niamey, by averaging the profiles made at the same time of the day (cases of precipitation are excluded). This figure is available in colour online at www.interscience.wiley.com/journal/qj 
for transition periods $\operatorname{Pr}$ and Po, because both factors (nocturnal jet and daytime convection) are stronger than during the $\mathrm{M}$ period, when deep convection disturbs those dry processes. (The diurnal cycle is barely detectable on $V$ during the $\mathrm{M}$ period).

The diurnal peak is also seen in the mid-troposphere at $3000 \mathrm{~m}$ during Pr and Po periods (Figures 5(a)-(c) and $6(\mathrm{a})-(\mathrm{c})$ ), but not during the $\mathrm{M}$ period (Figures $5(\mathrm{~b})$ and $6(\mathrm{~b}))$. There are two explanations for the diurnal signals at $700 \mathrm{hPa}$ : during the $\mathrm{Pr}$ and Po periods, the boundary layer can easily reach depths above $3000 \mathrm{~m}$, which then appears as a strong diurnal variability of the wind at this height. But the AEJ itself has a diurnal cycle, which contributes to the same 1-day period peaks in Figures 5(a)-(c) and 6(a)-(c). Indeed the spectra at $4500 \mathrm{~m}$ a.g.1. give the same results (not shown). The diurnal cycle of the AEJ will be analysed more thoroughly in the next section. It is also interesting to note that the peaks due to the diurnal cycle in Pr and Po periods at $3000 \mathrm{~m}$ are as high as they are at $500 \mathrm{~m}$ for the $V$ component, but smaller for $U$.

During the D period, the diurnal cycle peak is clearly seen at the low level on both components. The nocturnal jet (easterly wind then) is very strong during this season, as previously shown by Lothon et al. (2008). There is no sign of a diurnal cycle at $3 \mathrm{~km}$, which is consistent with the fact that the interaction between the PBL and the mid-troposphere discussed earlier cannot be seen during this season, as the wind within and above the PBL has the same direction (east) and the PBL depth usually does not reach $3 \mathrm{~km}$.

Finally, we can observe a distinct peak at a period of 12 hours during the D period at the low level for both wind components. This time-scale corresponds to the well-known manifestation of the semi-diurnal (SD) atmospheric tide, particularly strong at latitudes close to the Equator. Atmospheric tides resulting from the diurna thermal cycle are not a local phenomenon but rather the result of an overall oscillation of the whole atmosphere (Chapman and Lindzen, 1970).

The spectral analysis of the wind components at two levels brought out the main processes at different scales, including AEW activity, surges of monsoon and the diurnal cycle of the WAM. They also reveal the interactions between the mid and low troposphere at the intraseasonal scales that are the focus of the next section.

\section{Interaction between middle and lower tropo- sphere}

\subsection{Diurnal scale}

Figure 7 shows four composite days of the horizontal wind vertical profiles over Niamey averaged over the $\mathrm{Pr}$, $\mathrm{M}$, Po and D seasons with superimposed PBL depth, $Z_{i}$, and level of minimum wind (LMW) between monsoon and harmattan flows. The four seasons are identical to those used in the spectral analysis - that is, they are specific to Niamey. The figure gives a synthetic picture of the diurnal cycle during each season and emphasizes the relative evolutions of both the PBL and the AEJ over the course of the day. The averaged diurnal cycle of $Z_{i}$ was obtained from the $C_{n}{ }^{2}$ composite day. The standard deviation indicated on the $Z_{i}$ curve is calculated from all series of $Z_{i}$ over the considered season. The mean LMW is deduced from the composite day of the horizontal wind, as an index of the change from the lower westerlies to the upper easterlies (it is defined only in the Pr and M periods). Note that the days with deep convection and rain are not considered here.

During the Pr period (Figure 7(a)), the PBL grows deeply and quickly, due to the large net radiation and the dry ground, which gives large sensible heat fluxes at the surface. From surface measurements over two different vegetation covers (fallow and millet) in Wankama, Ramier et al. (2009) found a daily-average Evaporative Fraction $(\mathrm{EF})$ (equal to the ratio of latent heat flux to the sum of sensible and latent heat fluxes) close to zero in April and May, and ranging from 0 to 0.4 in June and early July due to sparse rain events. These surface measurements are in close agreement with sensible and latent heat flux vertical profiles deduced from aircraft measurements performed between 1200 and 1400 UTC and extrapolated to the surface (Saïd et al., 2009), which yield $\mathrm{EF} \approx 0.2$ in June in the middle of the day. Because of surface energy partitioning in favour of sensible heat flux, $Z_{i}$ reaches $2.5 \mathrm{~km}$ on average, with a large scatter (standard deviation is about half of the depth) due to varying aerosol concentration, cloud cover and rain events in June and July. It can be observed that, on average, the PBL grows within the monsoon flow in the morning and its top rises above the sheared interface between the monsoon and the easterlies after 1400 UTC. This favours the momentum transfers and scalar exchanges between the monsoon and the Saharan Air Layer (SAL) above, especially through the entrainment process, i.e. the intrusion of free atmosphere (SAL) dry air into the moister PBL (Canut et al., 2009; Lohou et al., 2009) and penetrative updraughts. The result is a drying of the PBL, moistening of the middle troposphere and a decrease of the wind, especially in the PBL. Likely as a result of this interaction between the PBL and the mid-troposphere through the turbulent mixing between two flows with opposite directions, both the easterly winds between 1000 and 1800 UTC at all levels from 1.5 up to $4 \mathrm{~km}$ height and the southerly wind in the PBL decrease. Although the effect on the wind speed at the AEJ lower flank is obvious, the decrease of the wind in the PBL by momentum transfer from the free troposphere is difficult to quantify because it is concomitant and added to the diurnal decrease of the wind in the PBL due to the turbulent mixing.

The Po period is quite similar to the Pr period, with deep and rapidly growing PBL. However, $Z_{i}$ is on average lower during the Po compared to the Pr period (2 instead of $2.5 \mathrm{~km}$ ). This is partly due to larger EF, which progressively decreases during this period because of the drying of the soil. At the beginning of the season, EF at Wankama remains constant around 0.5 and decreases down to 0.16 at the end of November (Ramier et al., 
2009). According to Figure 7(c), the entire low and midtroposphere is occupied by easterlies, due to the return of the harmattan in the low troposphere associated with the retreat of the ITD to the south.

During the $\mathrm{M}$ period, the AEJ is more centred over the region, so it appears stronger on the composite day (Figure 7(b)). The nocturnal jet is less strong during that period than during the Pr period, mainly due to the occurrence of deep convection. The level of minimum wind or turning flow is almost constant over the entire day, and $Z_{i}$ hardly reaches it on average (around $1 \mathrm{~km}$, with smaller scatter than during other periods) due to wet ground. Surface measurements and aircraft data match very well during that period and both provide EF of 0.8 based on daily averages of the surface estimates (Ramier et al., 2009) and half-hour averages of the estimates made with aircraft measurements (Saïd et al., 2009). Furthermore, the development of a thinner PBL included within the monsoon flow, due to smaller surface sensible heat flux, considerably reduces the chance of PBL warming and deepening by entrainment, because the conditions above the PBL top are identical to those of the monsoon flow. The entrainment flux ratio (equal to the buoyancy flux at the PBL top divided by the surface buoyancy flux) measured by the aircraft varies from 0.2 to 0.5 in June to close to 0 or 0.1 in August (Canut et al., 2009). A decrease of the AEJ wind speed starting at 1500 UTC, at the level of its maximum, can still be observed. However, the decrease on the AEJ lower flank previously observed during Pr and Po periods can no longer be seen. Thus, the diurnal influence of the PBL on the AEJ during the $\mathrm{M}$ period is almost non-existent compared to the $\mathrm{Pr}$ and Po periods.

During the D period, the diurnal cycle in the lower troposphere is very pronounced, with a strong easterly nocturnal jet (harmattan), and a decrease of the wind during the day accompanied by dry convection. Turbulent mixing is however less efficient than it is in the Pr and Po periods, because the downward solar radiation is smaller, and the radiative impact of aerosols is larger (daily net

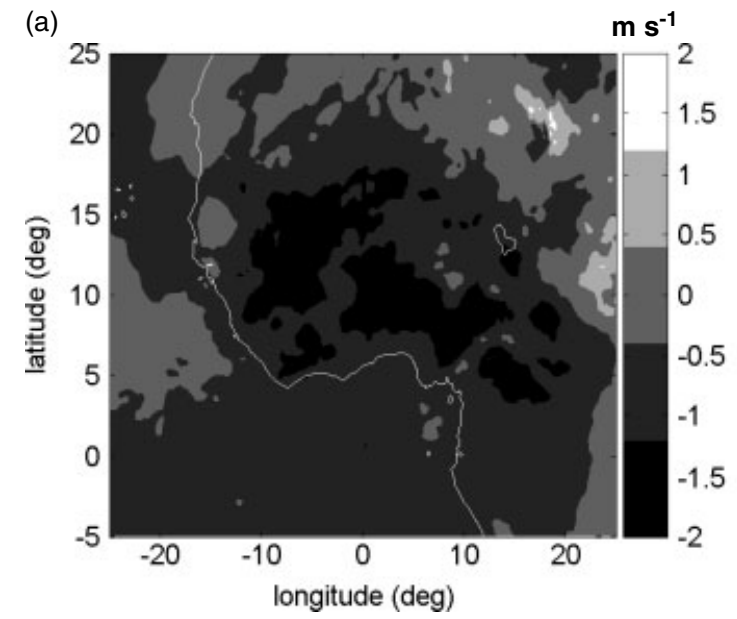

radiation of $20 \mathrm{~W} \mathrm{~m}^{-2}$ in the $\mathrm{D}$ period and $50 \mathrm{~W} \mathrm{~m}^{-2}$ in the $\operatorname{Pr}$ and Po periods), despite close-to-zero EF at Wankama at that time (Ramier et al., 2009). Note that the PBL cannot have the same interaction with the STJ as with the AEJ in other seasons, because the STJ is generally higher (its lower flank is around $4 \mathrm{~km}$ height). There is a $2 \mathrm{~km}$ deep layer of light wind in between the PBL top and the lower flank of the STJ (Figure 7(d)). Note, however, that our analysis of this period is limited by a lack of data above $3.5 \mathrm{~km}$, due to extremely dry air, which reduces the radar echo intensity. So the composite day may not be representative above $3.5 \mathrm{~km}$. This season is very different for several aspects and will not be discussed further here.

Many components of the WAM have a diurnal cycle, and Figure 7 shows that even the AEJ has one, with a minimum of wind speed around 1800 UTC, at the end of the afternoon, and a maximum around 0800 UTC (in $\mathrm{M}$ and Po periods) or 1000 UTC (in the M period). The ITD moves back and forth, northward and southward, during the night and day, respectively; this fluctuation is associated with the advection of moist and cool air during the night and the dissipation of the thermal gradient with turbulent mixing during the day (Pospichal and Crewell, 2007; Lothon et al., 2008). One might think that as a result of the diurnal cycle and spatial displacement of the HL and ITD, the AEJ might also have a meridional diurnal oscillation which would explain the evolution of the AEJ wind speed seen in Figure 7. In fact, the ECMWF analyses showed that this afternoon decrease in wind speed is not associated with a meridional move. Instead, the entire region of West Africa shows a decrease of the easterlies at 1800 UTC and an increase at 1200 UTC relative to the average over a 24 -hour cycle, as seen in Figure 8. This figure shows, at $700 \mathrm{hPa}$ and for the month of June, the monthly anomaly of the zonal component at a given time relative to the daily average (made with all ECMWF times considered, 0000, 0600, 1200 and 1800 UTC). Figure 8(b) does not show any north-south dipole that would reveal a meridional move of the AEJ core

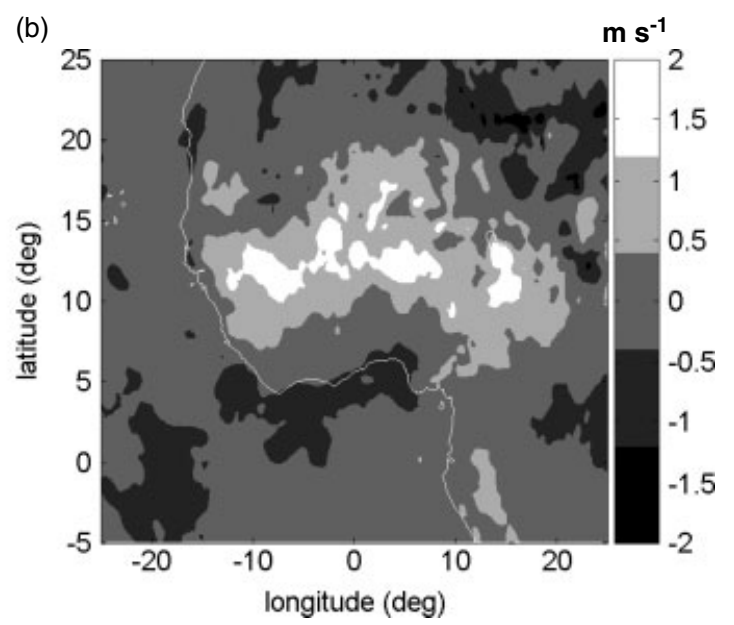

Figure 8. Anomaly of the easterly component at $700 \mathrm{hPa}$ in June at (a) 1200 UTC and (b) 1800 UTC relative to the monthly average made over all times of the day, based on ECMWF analyses. Note that a negative (positive) anomaly means an increase (a decrease) of the easterly wind speed. 
associated with this time-scale. We find a similar pattern for other months, with varying anomaly: a maximum of the anomaly is found at 1800 UTC in June $\left(1.8 \mathrm{~m} \mathrm{~s}^{-1}\right.$ on average, that is, $17 \%$ of the daily average) and a minimum in September $\left(0.5 \mathrm{~m} \mathrm{~s}^{-1}\right.$, that is, $\left.5 \%\right)$. It is also quite significant in May $\left(1.2 \mathrm{~m} \mathrm{~s}^{-1}\right.$, i.e. $\left.20 \%\right)$ and July $(1.3 \mathrm{~m}$ $\mathrm{s}^{-1}$, i.e. $14 \%$ ).

Due to its association with a temperature and moisture meridional gradient, the AEJ is expected to respond to changes in the heat-low intensity. As an increase of temperature in the Sahara will increase the meridional gradient, the AEJ wind speed can be expected to be correlated with the Saharan HL to the north, at least to some extent and in some scales. However, the previous analysis shows that at the diurnal time-scale, the opposite is observed: during the day: as the HL and potential temperature $\left(\theta_{\mathrm{v}}\right)$ gradient increase, the AEJ wind speed decreases, within a significant depth, from the lower flank to its core. Figure 9 shows how they are related at both the intraseasonal and diurnal time-scales. As an index of the HL intensity and the thermal gradient at the origin of the AEJ, we consider the difference $\Delta \theta_{\mathrm{v}}$ at $925 \mathrm{hPa}$ between averaged $\theta_{\mathrm{v}}$ over the domain of $\left[5^{\circ} \mathrm{W}-5^{\circ} \mathrm{E}\right]$ and $\left[15^{\circ} \mathrm{N}-25^{\circ} \mathrm{N}\right]$ (northern domain) and averaged over $\left[5^{\circ} \mathrm{W}-5^{\circ} \mathrm{E}\right]$ and $\left[10^{\circ} \mathrm{S}-0^{\circ} \mathrm{N}\right]$ (southern domain). This variable was also used by Couvreux et al. (2009), along with the surface pressure minimum, as an estimate of the HL intensity. Due to the complexity of the pressure field (with sometimes several areas of secondary minima) relative to the temperature field (which is more zonal), and the close connection between them by definition of the HL, we chose $\theta_{\mathrm{v}}$ here as an index for the heatlow. Lavaysse et al. (2009a) also used the temperature at $850 \mathrm{hPa}$, which gives results very similar to those obtained by using the potential temperature at $925 \mathrm{hPa}$. We also consider the opposite of the zonal component ( $-U$, so that it is positive for easterlies) averaged at $700 \mathrm{hPa}$ over the domain $\left[5^{\circ} \mathrm{W}-5^{\circ} \mathrm{E}\right]$ and $\left[10^{\circ} \mathrm{N}-15^{\circ} \mathrm{N}\right]$ of maximum AEJ during the $\mathrm{M}$ period (and including Niamey). Both are obtained from ECMWF analyses and plotted in Figure 9 with a 3-day filter from early May to the end of September and at 6-hour time intervals. $\Delta \theta_{\mathrm{v}}$ shows a very marked diurnal cycle for each day with a minimum at 0600 UTC and maximum at 1800 UTC. The easterly component also displays a significant diurnal cycle, as shown previously, with minimum easterly wind speed at 1800 UTC. However, it is less consistent and regular. The hour 0600 UTC is not always the time of the maximum, which is often found at 1200 UTC in the ECMWF analysis, and consistent with the maximum found between 0800 and 1000 UTC with the profiler data (Figure 7). Thus, we find that at the diurnal time-scale, the AEJ does not respond to the variation of the HL; if it did, the easterly wind at $700 \mathrm{hPa}$ and $\Delta \theta_{\mathrm{v}}$ at $925 \mathrm{hPa}$ would be maximum at the same time of the day.

\subsection{Synoptic scale}

Contrary to what occurs during a diurnal cycle, the correlation between $\Delta \theta_{\mathrm{v}}$ and the zonal component is clear on a larger scale during the onset of the monsoon, from early May to mid-June. This is shown in Figure 9 (solid lines) and Figure 10, which quantify the correlation between both variables. The correlation is made between the two smoothed (3-day running average) series of Figure 9, over periods of 15 days. We find a correlation coefficient of about 0.7 during this first period. As the $\mathrm{HL}$ is setting up in May (with the increasing equivalent potential temperature gradient due to both the heating over the Sahara and the cooling of the sea surface in the Gulf of Guinea), the AEJ is also setting in over the Niamey area. Note that during that time, and as seen in section 3 , there is both a displacement northward and an increase of the maximum wind speed in the AEJ. Thus the AEJ and HL are linked together at the intraseasonal scale during the Pr period. The same positive correlation (0.5) can be observed again later in the M period from 15 July to the end of September, but it is smaller, perhaps as a result of deep convection accompanied by AEWs that weaken the AEJ. Between the two above-mentioned periods, there is a one-month period, from mid-June to mid-July, during which the AEJ and HL are out of phase (Figure 9). AEJ strength actually decreases, whereas the synoptic temperature gradient is intensified, which means that the AEJ is not driven by the HL during that period.

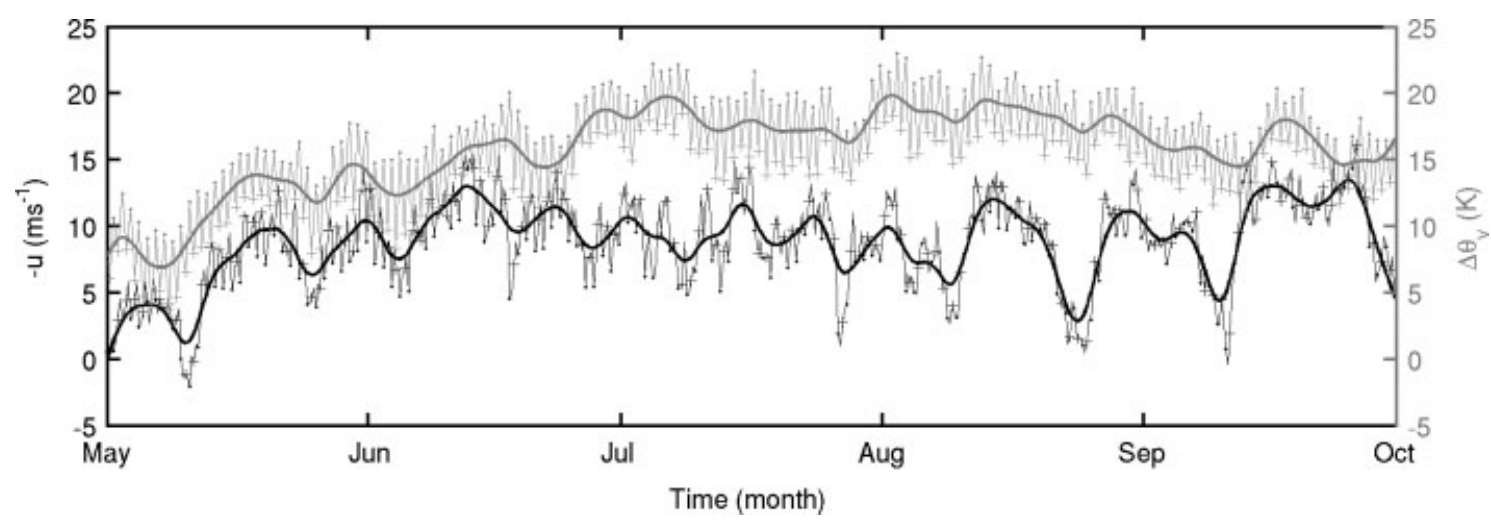

Figure 9. (black) Easterly component averaged between $10^{\circ} \mathrm{N}$ and $15^{\circ} \mathrm{N}$ latitude and between $5^{\circ} \mathrm{W}$ and $5^{\circ} \mathrm{E}$ and (grey) virtual potential temperature difference between $\left[5^{\circ} \mathrm{W}-5^{\circ} \mathrm{E}, 15^{\circ} \mathrm{N}-25^{\circ} \mathrm{N}\right]$ and $\left[5^{\circ} \mathrm{W}-5^{\circ} \mathrm{E}, 10^{\circ} \mathrm{S}-0^{\circ} \mathrm{N}\right]\left(\Delta \theta_{\mathrm{V}}\right)$. Thick lines are 3-day filtered series. Thin lines are 6 -hour time intervals, with dots indicating 1800 UTC and plus signs 0600 UTC. 


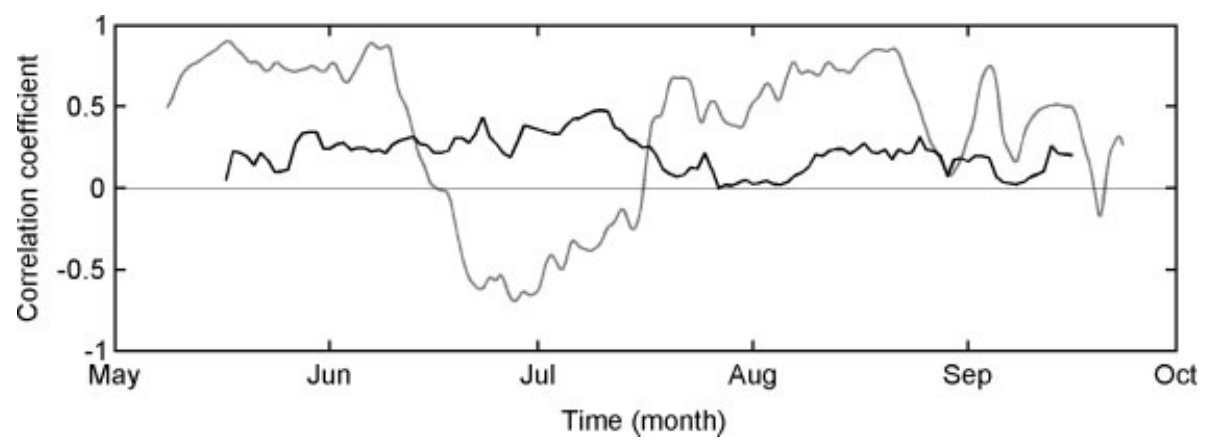

Figure 10. (grey) Correlation coefficient between the easterly component of the wind at $700 \mathrm{hPa}$ and $\Delta \theta_{\mathrm{v}}$ at $925 \mathrm{hPa}$ (smoothed time series shown in Figure 9). (black) Correlation coefficient between the diurnal easterly component anomaly of the wind (Figure 9) and $Z_{i}$ (Figure 11).
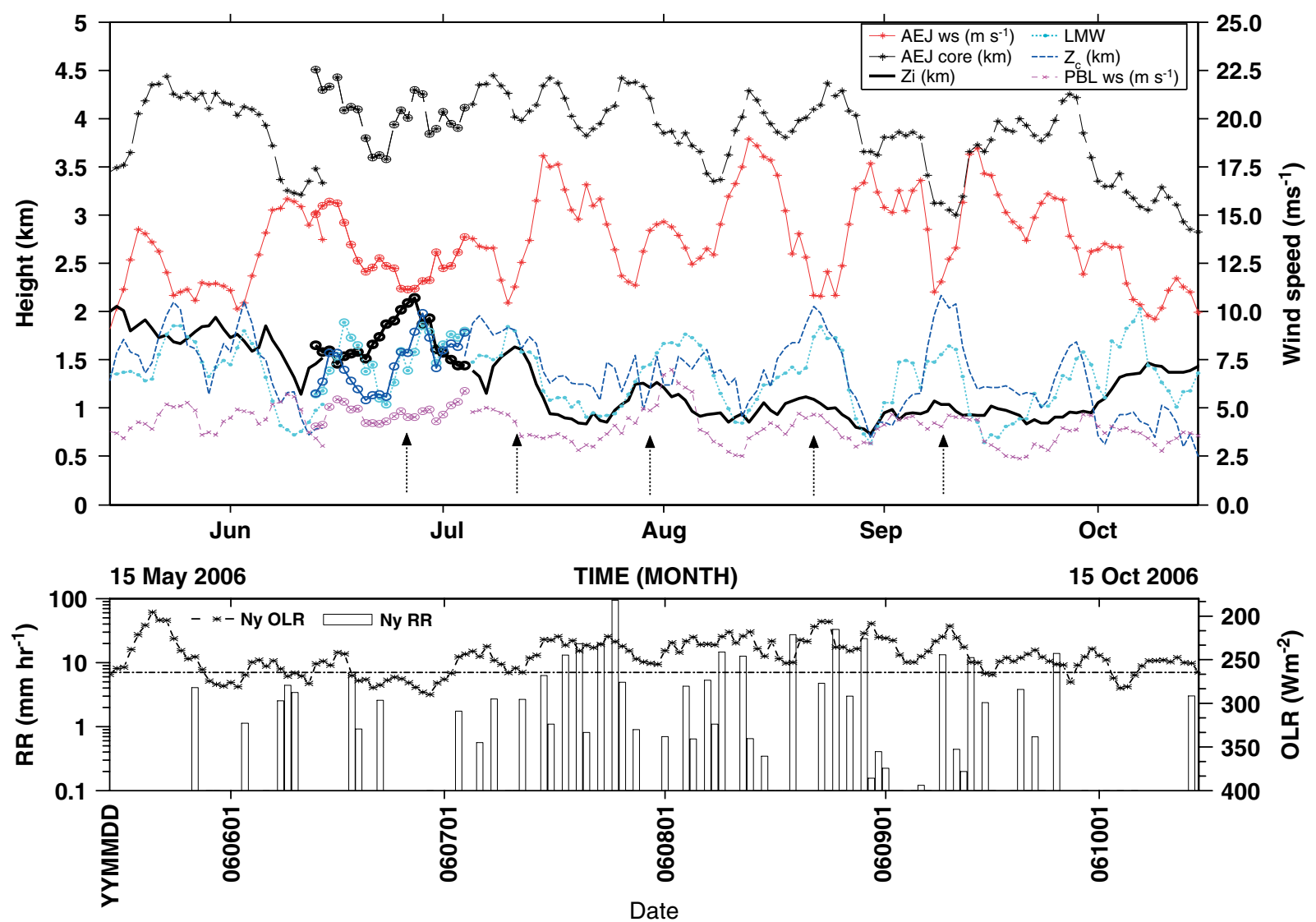

Figure 11. Top panel: time series of (thick black line) maximum $Z_{i}$, (red) maximum AEJ wind speed and (dotted black line) AEJ core height at the time of $Z_{i}$ maximum, (blue) $Z_{c}$, (cyan) LMW, and (magenta, crosses) mean PBL wind, all averaged between 1100 and 1700 UTC. Radiosounding measurements (circles) were used during the profiler data gap. In this case, $Z_{i}$ was obtained from the sharp gradient of potential temperature at the top inversion. Bottom panel: (bars) daily accumulated rain and (asterisks) outgoing long-wave radiation. This figure is available in colour online at www.interscience.wiley.com/journal/q

Finally, we show in Figure 11 how the AEJ and the PBL interact at the intraseasonal scale, based on 24hour interval estimates made from the measurements of the UHF wind profiler in Niamey (so that it does not include the diurnal time-scale). Note that for the period when the profiler did not work (17 June to 2 July), we completed the observations with Niamey radiosoundings. The AEJ wind speed maximum, the AEJ core height, the maximum $Z_{i}$ reached during the day, the PBL wind speed (averaged over its entire depth and over 1100-1700 UTC) and two levels indicating the vertical wind shear at the interface between the monsoon westerlies and the AEJ (LMW and $Z_{\mathrm{c}}$ ) are plotted on the same figure from mid-May to mid-October; that is, during the period when the AEJ is observed over Niamey (see Figure 3). LMW is the level of wind speed minimum mentioned previously and $Z_{\mathrm{c}}$ is the level at which the wind changes with increasing height from a southwesterly sector $\left(135^{\circ}-345^{\circ}\right)$ to any other direction. We also used other diagnostics based on the shear modulus and searched for maximum shear (not shown). As the interface between the monsoon flow and the SAL is difficult to detect, these various diagnostics help us to situate the PBL top relative to the wind flows 
and shears. When they are close together, they give reliable estimates of the height of the interface. The two estimates of the sheared interface height (LMW and $Z_{\mathrm{c}}$ ) shown in Figure 11 are averaged between 1100 and 1700 UTC, while the AEJ characteristics are those taken at the time of $Z_{i}$ maximum. The daily accumulated rainfall given by the ARM meteorological station (at Niamey airport) and the Outgoing Longwave Radiation (OLR) data around Niamey from the National Oceanic and Atmospheric Administration (http://www.cdc.noaa.gov) are also indicated (bottom panel).

At first glance, this figure shows the slow decrease of the maximum PBL depth from mid-May to the end of August from around $2.5 \mathrm{~km}$ to $1.2 \mathrm{~km}$. Within this large-scale trend, four main oscillations of $Z_{i}$ and the PBL mean wind are observed, connected to the rainfall observed by the ARM station (smaller $Z_{i}$ when more intense precipitation events occur). These oscillations are out of phase with the AEJ wind speed: a deep PBL is associated with weakened and low AEJ. The relationship previously mentioned at the daily time-scale between AEJ and PBL is therefore also observed at the intraseasonal scale. Their correlation is quantified in Figure 10. It is smaller than the correlation found between the AEJ diurnal decrease and the HL, but still significant. The increase of the correlation coefficient from mid-May (0.2) to around 10 July $(0.4)$ is consistent with the increasing impact of the PBL during the one-month period from mid-June to mid-July (discussed later), until the monsoon has set in and deep convection occurs and reduces the intensity and role of dry turbulence. It is also consistent with the increase of the AEJ diurnal anomaly quantified in section 4.1 (Figure 8). The concomitance of increasing $Z_{i}$, increasing PBL mean wind and decreasing AEJ is due to momentum transfer between the PBL and the SAL. Aircraft measurements of momentum made below and above the PBL top showed larger momentum transfers when $Z_{i}$ is higher than $Z_{\mathrm{c}}$ (not shown), lending further support to this explanation.

We now base our analysis of Figures 9, 10 and 11 on the three sub-periods introduced previously by Figure 9:

(1) From mid-May to mid-June, $Z_{i}$ is always above the shear region (between the lower westerly monsoon and upper easterlies of the SAL). The PBL turbulent mixing conditions are optimized to allow the momentum transfer between the PBL and AEJ, but the jet is in the process of setting up over Niamey and the variations seen in Figure 11 are closely linked with the growing intensity of the HL (Figure 9). Thus, the two processes compete and the anti-correlation between AEJ wind speed and $Z_{i}$ becomes shaded. However, the correlation between the diurnal decrease and $Z_{i}$ increases slightly during that time (Figure 10).

(2) From mid-June to mid-July, as the AEJ may no longer be driven by the HL (Figure 9), the PBL can have more influence. During that time, the PBL is still highly turbulent because it has not yet rained significantly and the surface heating is still large. We observe that $Z_{i}$ almost always rises above the shear level during that period. That is, the PBL can interact more easily with the jet and weaken it. This is confirmed by the maximum of correlation between the diurnal decrease of the AEJ and $Z_{i}$ (Figure 10).

(3) From mid-July to October, right after the monsoon onset, deep convection starts to become significant and the conditions change completely. The link between HL and AEJ starts to recover, with a slight correlation between both (Fig. 9). Also, the correlation between the diurnal decrease of the AEJ and $Z_{i}$ is close to zero at the beginning of this period (Figure 10). However, the coefficient increases after 10 August (Figure 10) and even during this active phase of the $M$ period, the minima of AEJ wind speed are associated with maxima of $Z_{i}$ (Figure 11). This is more difficult to explain, as the mixing in the PBL is growing within the moist monsoon flow on wet ground, and can hardly reach $1000 \mathrm{~m}$, or $1500 \mathrm{~m}$ at most. It is less energetic, and $Z_{i}$ cannot always reach the shear. In this case, a decrease of the jet can allow the PBL to grow faster. But the correlation can also be due to the general synoptic conditions leading to outof-phase variability of the AEJ and PBL without definite interaction.

According to ECMWF analyses, the variability of the AEJ wind speed is not obviously associated with a meridional move of the AEJ, but rather with a deepening or squeezing of the jet over latitude with time (not shown), and is concomitant with changes in the general circulation. Also, the minima found around 10 July, 22 August, 9 September and 27 September are all concomitant with large-scale dry intrusions (Roca and Deme, 2007). Dry intrusions occur at around $5 \mathrm{~km}$ height and can inhibit deep convection, which then allows the dry convection and the PBL to increase. Moreover, those large-scale dry intrusions usually come from the midlatitudes and may reduce the AEJ wind speed. This in turn would make the PBL deeper. On the other hand, a strong AEJ jet can favour deep convection because of the divergence induced by the resulting shear between low and mid-troposphere. This would result in a thinner PBL. However, it is complicated by the fact that deep convection has negative feedback on the AEJ, at least at the scale of the MCS itself. As an example of this complexity, both the maximum of AEJ wind speed on 12 August and the minimum close to the end of July (Figure 11) are associated with Mesoscale Convective Systems (MCSs) over Niamey (Barthe et al., 2009; Chong, 2009).

\section{Conclusions}

Wind profiler observations over Niamey and Djougou completed by ECMWF analyses allow us to study the 
intraseasonal variability of the low and mid-troposphere at several scales, down to the diurnal scale. Both sites, $450 \mathrm{~km}$ apart, give a continuous view of the AEJ from two different perspectives, since the AEJ crosses the latitude of Djougou during the monsoon onset and retreat, whereas it is set over the latitude of Niamey during the active monsoon phase.

VHF radar observations over Djougou can cover midand upper-atmospheric features but not the PBL, whereas UHF radar observations can cover both PBL and AEJ. Hence, the analysis was pursued further in Niamey, where the measurements of the UHF cover the low and mid-troposphere for most of the year. The predominant processes vary with the season, with different impacts on the interaction between the AEJ and the PBL. We also find that both wind components play a distinct role in this variability.

We find a pronounced diurnal cycle of the AEJ at $700 \mathrm{hPa}$, in addition to the diurnal cycle of the low layers, which is well known and due to both the existence of a nocturnal jet and daytime dry convection, which weakens the wind. The height of the AEJ remains constant throughout the day. The diurnal variation of the AEJ is mainly a decrease of the wind speed during the afternoon, reaching a minimum at 1800 UTC on average. This decrease is out of phase with the HL diurnal variability, but in phase with the daytime turbulent mixing that occurs within the PBL, which tends to homogenize two flows with opposite directions. It is at its maximum in May and minimum in August and September. This is consistent with the fact that during the Pr period, when surface heating is large and deep convection is not yet present, momentum transfers between mid- and low troposphere are favoured, especially when the PBL top rises above the shear zone between the monsoon and the easterlies. Mixing between the PBL and midtroposphere is responsible for the daily decrease of the AEJ.

At scales ranging from 3 to 10 days, we find the footprint of the AEWs activity during the $M$ period on both wind components in the mid-troposphere, and of the monsoon surges during the Pr and Po periods in lower layers through fluctuations of the meridional component. At those scales, the interaction between the AEJ and the PBL is difficult to explain. During the transition periods, Pr and Po, the AEJ seems to be tightly connected to the HL. The link with the PBL at those scales is unclear; however, we believe that the dry convective mixing PBL processes may also weaken the AEJ at those larger timescales. During the early M period, before the persistent rain that truly characterizes the monsoon season, the HL seems no longer to have any direct influence on the AEJ, so that the PBL may have a greater impact, as at the diurnal time-scale. In the active $\mathrm{M}$ period (after the onset), deep convection, AEWs, dry intrusions etc. make the synoptic environment complex and blur the interaction between AEJ and PBL. We still find weaker AEJ for deeper PBL, but likely without any direct connection between them.

\section{Acknowledgements}

Based on a French initiative, AMMA was built by an international scientific group and is currently funded by a large number of agencies, especially from France, UK, US and Africa. It has been the beneficiary of a major financial contribution from the European Community's Sixth Framework Research Programme. Detailed information on scientific co-ordination and funding is available on the AMMA International web site http://www.ammainternational.org. We thank Sophie Bourlès (IPSL) for help in extracting the ECMWF data. We want to give special thanks to the cooperation of the US Department of Energy as part of the Atmospheric Radiation Measurement Program for operating the UHF wind profiler in Niamey and providing the data. The first author has benefited from a postdoctoral fellowship funded by Institut National des Sciences de l'Univers (INSU) and Centre Nationale de la Recherche Scientifique (CNRS) in France. We thank Debra Bellon for checking the language. We gratefully thank the two reviewers and associate editor for their thorough and relevant review.

\section{References}

Adachi A, Kobayashi T. Gage KS, Carter DA, Hartten LM, Clark WL, Fukuda M. 2005. Evaluation of three-beam and four-beam profiler wind measurement techniques using a five-beam wind profiler and collocated meteorological tower. J. Atmos. Oceanic Technol. 22: 1167-1180.

Angevine WM, White AB, Avery SK. 1994. Boundary-layer depth and entrainment zone characterization with a boundary-layer profiler. Boundary-Layer Meteorol. 68: 375-385.

Balsley BB, Gage KS. 1982. On the use of radars for operational wind profiling. Bull. Am. Meteorol. Soc. 63: 1009-1018.

Barthe C, Asencio N, Lafore J-P, Chong M, Campistron B, Cazenave F. 2009. Multi-scale analysis of the 25-27 July 2006 convective period over Niamey: Comparison between Doppler radar observations and simulations. Q. J. R. Meteorol. Soc. 136(s1): 191-209.

Bock O, Bouin MN, Doerflinger E, Collard P, Masson F, Meynadier R, Nahmani S, Koité M, Gaptia Lawan Balawan K, Didé F, Ouedraogo D, Pokperlaar S, Ngamini J-B, Lafore J-P, Janicot S, Guichard F, Nuret M. 2008. West African monsoon observed with ground-based GPS receivers during African Monsoon Multidisciplinary Analysis (AMMA). J. Geophys. Res. 113: D21105, DOI:10.1029/2008JD010327.

Burpee RW. 1972. The origin and structure of easterly waves in the lower troposphere of North Africa. J. Atmos. Sci. 29: 77-90.

Cadet DL, Nnoli NO. 1987. Water vapour transport over Africa and the Atlantic Ocean during summer 1979. Q. J. R. Meteorol. Soc. 113: $581-602$.

Canut G, Lothon M, Saiid F. 2009. Observation of entrainment at the interface between monsoon flow and Saharan Air Layer. Q. J. R. Meteorol. Soc. 136(s1): 34-46.

Chapman S, Lindzen RS. 1970. Atmospheric tides. D. Reidel: Dordrecht.

Chong M. 2009. The 11 August 2006 squall-line system as observed from MIT Doppler radar during the AMMA SOP. Q. J. R. Meteorol. Soc. 136(s1): 210-227.

Cook KH. 1999. Generation of the African Easterly Jet and its role in determining West African precipitation. J. Climate 12: 1165-1184.

Couvreux F, Guichard F, Bock O, Campistron B, Lafore J-P, Redelsperger J-L. 2009. Synoptic variability of the monsoon flux over West Africa prior to the onset. Q. J. R. Meteorol. Soc. 136(s1): $160-174$.

Diedhiou A, Janicot S, Viltard A, de Felice P, Laurent H. 1999. Easterly wave regimes and associated convection over West Africa and tropical Atlantic: Results from the NCEP/NCAR and ECMWF reanalyses. Clim. Dyn. 15: 795-822. 
Doviak RJ, Zrnic DS. 1993. Doppler radar and weather observations. Academic Press: Orlando. Pp 398-404.

Fink AH, Reiner A. 2003. Spatiotemporal variability of the relation between African easterly waves and West African squall lines in 1998 and 1999. J. Geophys. Res. 108: 4332, DOI: $10.1029 / 2002 J D 002816$.

Gossard EE, Chadwick RB, Neff WD, Moran KP. 1982. The use of ground-based Doppler radars to measure gradients, fluxes and structure parameters in elevated layers. J. Appl. Meteorol. 21 211-226.

Goutorbe J-P, Dolman AJ, Gash JHC, Kerr YH, Lebel T, Prince SD, Stricker JNM (eds). 1997. HAPEX-Sahel. J. Hydrol. 188-189: 1-4.

Hsieh J-S, Cook KH. 2008. On the instability of the African Easterly Jet and the generation of African waves: Reversals of the potential vorticity gradient. J. Atmos. Sci. 65: 2130-2151.

Jacoby-Koaly S, Campistron B, Bernard S, Bénech B, GirardArdhuin F, Dessens J, Dupont E, Carissimo B. 2002. Turbulent dissipation rate in the boundary layer via UHF wind profiler Doppler spectral width measurements. Boundary-Layer Meteorol. 103: $361-389$.

Kalapureddy MCR, Kishore Kumar K, Sivakumar V, Ghosh AK, Jain AR, Krishna Reddy K. 2007. Diurnal and seasonal variability of TKE dissipation rate in the ABL over a tropical station using UHF wind profiler. J. Atmos. Solar-Terr. Phys. 69: 419-430.

Kiladis GN, Thorncroft CD, Hall NMJ. 2006. Three-dimensional structure and dynamics of African easterly waves. Part I: Observations. J. Atmos. Sci. 63: 2212-2230.

Lavaysse C, Diedhiou A, Laurent H, Lebel T. 2006. African easterly waves and convective activity in wet and dry sequences of the West African monsoon. Clim. Dyn. 27: 319-332.

Lavaysse C, Flamant C, Janicot S, Parker DJ, Lafore J-P, Sultan B, Pelon J. 2009a. Seasonal evolution of the West African heat low: A climatological perspective. Clim. Dyn. 33: 313-330.

Lavaysse C, Flamant C, Janicot S, Knippertz P. 2009b. Impact of the midlatitude circulation on the intraseasonal pulsations of the West African heat-low: A spectra analysis. Submitted to Q. J. R. Meteorol. Soc.

Lohou F, Saïd F, Lothon M, Serça D. 2009. Planetary boundary layer processes signatures on turbulent characteristics and heat fluxes at surface. Submitted to Boundary-Layer Meteorol.

Lothon M, Saïd F, Lohou F, Campistron B. 2008. Observation of the diurnal cycle in the low troposphere of West Africa. Mon. Weather Rev. 136: $3477-3500$.

May PT. 1993. Comparison of wind-profiler and radiosonde measurements in the Tropics. J. Atmos. Oceanic Technol. 10: $122-127$.

Parker DJ, Burton RR, Diongue-Niang A, Ellis RJ, Felton MA, Taylor CM, Thorncroft CD, Bessemoulin P, Tompkins AM. 2005. The diurnal cycle of the West African monsoon circulation. Q. J.R. Meteorol. Soc. 131: 2839-2860.

Pospichal B, Crewell S. 2007. Boundary layer observations in West Africa using a novel microwave radiometer. Meteorol. Z. 16: $513-523$.
Pytharoulis I, Thorncroft CD. 1999. The low-level structure of African easterly waves in 1995. Mon. Weather Rev. 127: 2266-2280.

Ramier D, Boulain N, Cappelaere B, Timouk F, Rabanit M, Lloyd CR, Boubkraoui S, Métayer F, Descroix L, Wawrzyniak V. 2009. Towards an understanding of coupled physical and biological processes in the cultivated Sahel. 1: Energy and water. J. Hydrol., in press.

Rao TN, Rao DN, Mohan K, Raghavan S. 2001. Classification of tropical precipitating systems and associated $Z-R$ relationships. $J$. Geophys. Res. 106: 17699-17711.

Redelsperger J-L, Diongue A, Diedhiou A, Ceron J-P, Diop M, Gueremy J-F, Lafore J-P. 2002. Multi-scale description of a Sahelian synoptic weather system representative of the West African monsoon. Q. J. R. Meteorol. Soc. 128: 1229-1257.

Redelsperger J-L, Thorncroft CD, Diedhiou A, Lebel T, Parker DJ, Polcher J. 2006. African Monsoon Multidisciplinary Analysis (AMMA): An international research project and field campaign. Bull. Am. Meteorol. Soc. 87: 1739-1746.

Reed RJ, Norquist DC, Recker EE. 1977. The structure and properties of African wave disturbances as observed during Phase III of GATE. Mon. Weather Rev. 105: 317-333.

Roca R, Deme A. 2007. 'Dry intrusions in the African mid-troposphere during AMMA.' Celebrating the monsoon, an international conference, 24-28 July 2007, Bangalore, India.

Saïd F, Canut G, Durand P, Lohou F, Lothon M. 2009. Seasonal evolution of the boundary-layer turbulence measured by aircraft during AMMA 2006 Special Observation Period. Q. J. R. Meteorol. Soc. 136(s1): 47-65.

Sato $\mathrm{T}$, Doji $\mathrm{H}$, Iwai $\mathrm{H}$, Kimura I, Fukao $\mathrm{S}$, Yamamoto $\mathrm{M}$, Tsuda T, Kato S. 1990. Computer processing for deriving dropsize distributions and vertical air velocities from VHF Doppler radar spectra. Radio Sci. 25: 961-973.

Strauch RG, Merritt DA, Moran KP, Earnshaw KB, Van De Kamp D. 1984. The Colorado wind-profiling network. J. Atmos. Oceanic Technol. 1: 37-49.

Strauch RG, Weber BL, Frisch AS, Little CG, Merritt DA, Moran KP, Welsh DC. 1987. The precision and relative accuracy of profiler wind measurements. J. Atmos. Oceanic Technol. 4: 563-571.

Sultan B, Janicot S. 2000. Abrupt shift of the ITCZ over West Africa and intra-seasonal variability. Geophys. Res. Lett. 27: 3353-3356.

Thorncroft CD. 1995. An idealized study of African easterly waves. III: More realistic basic states. Q. J. R. Meteorol. Soc. 121: 1589-1614.

Thorncroft CD, Blackburn M. 1999. Maintenance of the African easterly jet. Q. J. R. Meteorol. Soc. 125: 763-786.

Thorncroft CD, Hodges K. 2001. African easterly wave variability and its relationship to Atlantic tropical cyclone activity. J. Climate 14: $1166-1179$.

Thorncroft CD, Parker DJ, Burton RR, Diop M, Ayers JH, Barjat H, Devereau S, Diongue A, Dumelow R, Kindred DR, Price NM, Saloum M, Taylor CM, Tompkins AM. 2003. The JET2000 project: Aircraft observations of the African Easterly Jet and African easterly waves. Bull. Am. Meteorol. Soc. 84: 337-351. 